\title{
Development of a parameterization of black carbon aging for use in general circulation models
}

\author{
N. Oshima ${ }^{1}$ and M. Koike ${ }^{2}$ \\ ${ }^{1}$ Meteorological Research Institute, 1-1 Nagamine, Tsukuba, Ibaraki, 305-0052, Japan. \\ ${ }^{2}$ Department of Earth and Planetary Science, Graduate School of Science, The University of Tokyo, 7-3-1 Hongo, \\ Bunkyo-ku, Tokyo, 113-0033, Japan
}

Correspondence to: N. Oshima (oshima@mri-jma.go.jp)

Received: 27 April 2012 - Published in Geosci. Model Dev. Discuss.: 16 May 2012

Revised: 31 January 2013 - Accepted: 31 January 2013 - Published: 1 March 2013

\begin{abstract}
A parameterization of black carbon (BC) aging in the atmosphere is developed for use in general circulation models (GCMs) that separately treat hydrophobic BC and hydrophilic $\mathrm{BC}$ modes but do not explicitly calculate the aging processes of $\mathrm{BC}$. The rate of $\mathrm{BC}$ aging is expressed as the conversion rate from hydrophobic $\mathrm{BC}$ to hydrophilic $\mathrm{BC}$ modes (i.e., inverse of the e-folding time of the conversion, $\left.1 / \tau_{\mathrm{BC}}\right)$. In this study, the conversion rates are estimated using results of detailed calculations by a size and mixing state resolved aerosol box model with numerous initial conditions. We introduce a new concept, the hydrophobic-BCmass-normalized coating rate $\left(V_{\mathrm{BC}}\right)$, defined as the rate of increase of the mass concentration of condensed materials on hydrophobic $\mathrm{BC}$ normalized by the hydrophobic $\mathrm{BC}$ mass concentration. Although the conversion rate largely varies depending on the atmospheric conditions and the concentrations of chemical species, we find that the variations of the conversion rate are generally expressed well by a unique function of $V_{\mathrm{BC}}$ for given lognormal size distributions of hydrophobic BC. The parameterized conversion rate is expressed as a function of $V_{\mathrm{BC}}$, which enables the representation of diurnal and seasonal variations of the $\mathrm{BC}$ aging rate and its spatial differences in polluted and clean air, while other widely used constant conversion rates cannot. Application of our newly developed parameterization to GCMs will provide more reliable estimates of the spatial distribution of $\mathrm{BC}$ and its radiative effects at regional and global scales.
\end{abstract}

\section{Introduction}

Most atmospheric aerosol components scatter solar radiation; however, black carbon (BC) aerosols efficiently absorb it and lead to heating of the atmosphere. Because of these light-absorbing effects, $\mathrm{BC}$ has been recognized as one of the most important aerosol types for climate forcing (e.g., Hansen et al., 1997; Ramanathan et al., 2001; Jacobson, 2001a; Menon et al., 2002; Koren et al., 2004; Ramanathan and Carmichael, 2008). BC particles are emitted into the atmosphere by incomplete combustion of fossil fuels, biofuels, and biomass. Freshly emitted BC particles generally have little coating materials on their surface and are therefore in a hydrophobic state (Weingartner et al., 1997; Sakurai et al., 2003), although some BC particles from diesel exhaust and biomass burning are internally mixed with organic species (Wehner et al., 2004; Toner et al., 2006; Adachi and Buseck, 2011). They gradually become internally mixed with other aerosols through condensation, coagulation, and photochemical oxidation processes in the atmosphere (aging processes). Internal mixing with sufficient water-soluble compounds changes initially hydrophobic $\mathrm{BC}$ to hydrophilic $\mathrm{BC}$, which is able to serve as cloud condensation nuclei (CCN) at a given supersaturation (e.g., Yu, 2000; Seinfeld and Pandis, 2006). Therefore, the aging processes of $B C$ increase the wet scavenging efficiency of BC-containing particles and influence the atmospheric lifetime of BC (Stier et al., 2006) through their removal from the atmosphere by precipitation (Oshima et al., 2012). At the same time, internal mixing with non-absorbing compounds enhances the $\mathrm{BC}$ absorption efficiency of solar radiation (Bond et al., 2006). 
Consequently, aging processes of $\mathrm{BC}$ particles play an important role for the spatial distributions of $\mathrm{BC}$ and its radiative effects.

Recently, the number of general circulation models (GCMs) that explicitly treat aerosol microphysics with a representation of the aerosol size distribution by modal or sectional methods has been growing rapidly. For example, GATOR-GCMM (Jacobson, 2001b), ECHAM5-HAM (Stier et al., 2005), ModelE-MATRIX (Bauer et al., 2008), WACCM/CARMA (Bardeen et al., 2008), EMAC/MADEin (Aquila et al., 2011), and CAM5-MAM7 (Liu et al., 2012) provide detailed representations of the aging processes of $\mathrm{BC}$ through condensation and coagulation, and some of these models are used for global climate simulations. However, there are still many GCMs that treat the BC aging processes as a simple time scale conversion from hydrophobic to hydrophilic states using the bulk method, in which only mass concentrations of aerosol species are predicted with the prescribed aerosol size distributions. For example, among a total of 15 models included in the Aerosol Model Intercomparison Initiative (AeroCom) Phase II direct aerosol effect experiment (Myhre et al., 2012), more than half either use a time scale conversion for the $\mathrm{BC}$ aging processes (e.g., HadGEM2; Bellouin et al., 2011; and NCARCAM3.5; Lamarque et al., 2012) or ignore BC aging processes altogether (e.g., GISS-ModelE (Koch et al., 2007) and SPRINTARS (Takemura et al., 2005)). Most models participating in the Atmospheric Chemistry and Climate Model Intercomparison Project (ACCMIP) (Lee et al., 2012) also treat the $\mathrm{BC}$ aging processes with the time scale conversion (e.g., GISS-E2-R; Koch et al., 2011, GFDL-AM3; Donner et al., 2011, and CICERO-OsloCTM2; Skeie et al., 2001). In addition to some of these models, there are several models that participate in the Climate Model Intercomparison Project phase 5 (CMIP5) in support of the Intergovernmental Panel on Climate Change (IPCC) Fifth Assessment Report (AR5) and treat $\mathrm{BC}$ aging processes with a simple time scale conversion (e.g., MRI-CGCM3; Yukimoto et al., 2012). For climate calculations with long time integration (decades to centuries) and/or with fine spatial resolution by coupled atmosphereocean global climate models, a simple parameterization that can capture the essentials of $\mathrm{BC}$ aging processes is still desirable due to limited computational resources, instead of the explicit treatment of aerosol microphysics in models, which are computationally expensive.

In the GCMs that treat aerosol species on the basis of the bulk method, the aging processes of $\mathrm{BC}$ particles are generally expressed as a conversion of $\mathrm{BC}$ from hydrophobic to hydrophilic modes with a characteristic time:

$$
\left(\frac{\partial\left[\mathrm{BC}_{\mathrm{phob}}\right]}{\partial t}\right)=-\frac{\left[\mathrm{BC}_{\mathrm{phob}}\right]}{\tau_{\mathrm{BC}}}
$$

$\left(\frac{\partial\left[\mathrm{BC}_{\mathrm{phii}}\right]}{\partial t}\right)=\frac{\left[\mathrm{BC}_{\mathrm{phob}}\right]}{\tau_{\mathrm{BC}}}$,

where $\left[\mathrm{BC}_{\mathrm{phob}}\right]$ and $\left[\mathrm{BC}_{\mathrm{phil}}\right]$ are the hydrophobic and hydrophilic $\mathrm{BC}$ mass concentrations, respectively, and $\tau_{\mathrm{BC}}$ is the e-folding time of the conversion. A simple approach using constant values of the conversion rate from hydrophobic $\mathrm{BC}$ to hydrophilic BC, such as 24 or $36 \mathrm{~h}$, has been widely used in several GCM studies (e.g., Cooke and Wilson, 1996; Cooke et al., 1999, 2002; Lohmann et al., 1999; Koch, 2001; Chung and Seinfeld, 2002; Bellouin et al., 2011; Donner et al., 2011; Lamarque et al., 2012), although the conversion rate is considered to vary depending on atmospheric conditions and concentrations of chemical species during the aging process. Previously, Koch (2001) and Wilson et al. (2001) calculated the variable conversion rates of $\mathrm{BC}$ aging depending on the condensation of sulfuric acid $\left(\mathrm{H}_{2} \mathrm{SO}_{4}\right)$, produced from gas-phase oxidation of sulfur dioxide $\left(\mathrm{SO}_{2}\right)$. Riemer et al. (2004) presented a detailed parameterization of BC aging using results of mesoscale aerosol model simulations that treated condensation and coagulation of several species of aerosols. They showed that the conversion time scale is $2 \mathrm{~h}$ above $250 \mathrm{~m}$ and $8 \mathrm{~h}$ below during daytime and a function of the number concentration of internally mixed particles during nighttime. However, their parameterization (i.e., the $\tau_{\mathrm{BC}}$ values of 2 and $8 \mathrm{~h}$ during daytime and Eq. (7) given by Riemer et al. (2004) during nighttime) will be applicable only for a polluted region over land (e.g., Germany). Recently, Liu et al. (2011) developed a parameterization of BC aging using a function of hydroxyl $(\mathrm{OH})$ radical concentration, defined as follows:

$$
\frac{1}{\tau_{\mathrm{BC}}}=\beta \cdot[\mathrm{OH}]+\delta
$$

where $\beta$ (i.e., a fast-aging term, such as condensation) and $\delta$ (i.e., a slow-aging term such as coagulation, assuming an efolding conversion time of 20 days) are constants with values $4.6 \times 10^{-12} \mathrm{~cm}^{3}$ molecule ${ }^{-1} \mathrm{~s}^{-1}$ and $5.8 \times 10^{-7} \mathrm{~s}^{-1}$, respectively, and $[\mathrm{OH}]$ is the $\mathrm{OH}$ radical concentration. However, use of a constant $\beta$ value in the fast-aging term neglects dependencies of $\mathrm{BC}$ aging on condensable materials and their precursors (e.g., $\mathrm{SO}_{2}$ ). Conversion rates have been recognized as one of the key uncertainties in estimating the impacts of BC on climate (Cooke et al., 2002; Chung and Seinfeld, 2005; Goto et al., 2012). Recent studies pointed out the necessity of an advanced parameterization of $\mathrm{BC}$ aging processes applicable to various atmospheric conditions in GCMs in order to improve the quantitative estimation of the climate impacts of BC (Wilson et al., 2001; Riemer et al., 2004; Croft et al., 2005; Liu et al., 2005; Park et al., 2005; Tsyro et al., 2007; Koch et al., 2009; Liu et al., 2011).

This study develops a new parameterization of the $\mathrm{BC}$ aging process for use in GCMs that separately treat hydrophobic $\mathrm{BC}$ and hydrophilic $\mathrm{BC}$ modes and treat aerosol species on the basis of the bulk method. In this study, we focus on 
the condensation process, because it is one of the most important $\mathrm{BC}$ aging processes under most atmospheric conditions. The new parameterization is expressed as the conversion rate of $\mathrm{BC}$ particles from hydrophobic $\mathrm{BC}$ to hydrophilic $\mathrm{BC}$ modes, using results of detailed calculations by a size and mixing state resolved aerosol box model (Sects. 2 and 3). A method for applying our parameterization to GCMs is described in Sect. 4. Variations of $\tau_{\mathrm{BC}}$ due to changes in atmospheric conditions and concentrations of chemical species derived from the calculations are shown in Sect. 5. Estimates of the time scale of $\mathrm{BC}$ aging due to coagulation and recommended treatments of the coagulation effects in our parameterization are described in Sect. 6 and Appendix A.

\section{Methodology}

\subsection{MADRID-BC}

In this study, we use the Model of Aerosol Dynamics, Reaction, Ionization, and Dissolution (MADRID) (Zhang et al., 2004) with resolution of the mixing state of BC (MADRID-BC) (Oshima et al., 2009a). MADRID-BC is a stand-alone size and mixing state resolved aerosol box model that includes the gas-phase chemistry of the Carbon-Bond Mechanism Version IV (CBM-IV) photochemical mechanism (Gery et al., 1989). Photolysis rates of chemical reactions treated in the Community Multiscale Air Quality (CMAQ) model are utilized in MADRID-BC (Byun and Ching, 1999). Heterogeneous reactions on the surface of particles are also included in MADRID-BC (Zhang et al., 2004), in which the median values of the uptake coefficient $(\gamma)$ recommended by Jacob (2000) are used (i.e., $\gamma_{\mathrm{HO}_{2}}=0.2$, $\gamma_{\mathrm{NO}_{2}}=10^{-4}, \gamma_{\mathrm{NO}_{3}}=10^{-3}$, and $\gamma_{\mathrm{N}_{2} \mathrm{O}_{5}}=0.1$ ). MADRID$\mathrm{BC}$ uses a two-dimensional (2-D) aerosol representation in which aerosol mass and number are given for individual ranges of particle diameters and $\mathrm{BC}$ mass fractions (see Oshima et al., 2009a, Fig. 1). In addition to BC-containing particles, externally mixed BC-free particles are represented separately. In the 2-D aerosol representation, the diameter and $\mathrm{BC}$ mass fraction of particles can vary between the low and high edges of the size and $\mathrm{BC}$ mass fraction bins, respectively, and the transfer of particle number and mass due to their growth and shrinkage can be simulated simultaneously in both directions (i.e., particle diameter and BC mass fraction) on the basis of the moving center approach (Jacobson, 1997). Aerosol species treated in MADRID-BC include sulfate $\left(\mathrm{SO}_{4}^{2-}\right)$, ammonium $\left(\mathrm{NH}_{4}^{+}\right)$, nitrate $\left(\mathrm{NO}_{3}^{-}\right)$, sodium $\left(\mathrm{Na}^{+}\right)$, chloride $\left(\mathrm{Cl}^{-}\right)$, aerosol water, $\mathrm{BC}$, and organic matter (OM). MADRID-BC treats mass transfer between gas and particulate phases using a dynamic (kinetic) non-equilibrium approach developed by Meng et al. (1998), and it enables accurate calculations of the time evolution of the entire $\mathrm{BC}$ mixing state resulting from condensation/evaporation processes. Condensation/evaporation involving secondary organic aerosols (SOAs) and their precursors is not included in the dynamic approach in MADRID-BC, although the method presented in this paper can be extended when SOAs and their precursors are included in condensable materials (see Sect. 3.3). The BC aging processes due to coagulation and photochemical oxidation are not included in MADRID-BC, although contributions of coagulation to BC aging may be important under certain circumstances (e.g., over source regions and during nighttime) (Riemer et al., 2010). The effects of coagulation on $B C$ aging are described in Sect. 6 and Appendix A. MADRID-BC treats homogeneous nucleation processes (Zhang et al., 2004); however, they are not used in this study. The dilution of air, dry and wet deposition, and aqueous-phase chemistry in cloud particles are not included in MADRID-BC. Meteorological conditions (e.g., air density, pressure, temperature $(T)$, relative humidity (RH), and cloud/rain information) are kept constant throughout each MADRID-BC calculation.

MADRID-BC calculates the critical supersaturation of particles using the Köhler equation (Seinfeld and Pandis, 2006), in which the saturation ratio, $S$, at equilibrium over an aqueous solution droplet is expressed as

$\ln S=\frac{A}{D_{\text {drop }}}-\frac{B}{\left(D_{\text {drop }}^{3}-d_{\text {core }}^{3}\right)}$,
where

where

$A=\frac{4 M_{\mathrm{w}} \sigma_{\mathrm{w}}}{R T \rho_{\mathrm{w}}}, B=\frac{6 n_{\mathrm{s}} M_{\mathrm{w}}}{\pi \rho_{\mathrm{w}}}$,

$n_{\mathrm{S}}=\frac{\left(1-\varepsilon_{\text {core }}\right)}{M_{\mathrm{S}}} \frac{v \pi d_{\mathrm{s}}^{3}}{6\left(\frac{1-\varepsilon_{\text {core }}}{\rho_{\mathrm{s}}}+\frac{\varepsilon_{\text {core }}}{\rho_{\text {core }}}\right)}$

and $D_{\text {drop }}, d_{\text {core }}$, and $d_{\mathrm{s}}$ are the volume equivalent diameters of droplet, core, and dry particles, respectively, $\sigma_{\mathrm{w}}$ is the surface tension of water, $M_{\mathrm{w}}$ and $M_{\mathrm{S}}$ are the molecular weights of water and solute, respectively, $\rho_{\mathrm{w}}, \rho_{\mathrm{s}}$, and $\rho_{\text {core }}$ are the densities of water, solute, and core, respectively, $v$ is the van't Hoff factor, and $\varepsilon_{\text {core }}$ is the insoluble mass fraction (i.e., $\mathrm{BC}$ mass fraction). $\mathrm{BC}$ is treated as an insoluble concentric core for BC-containing particles, and other aerosol components are assumed to be soluble materials that condense onto $\mathrm{BC}$-containing and $\mathrm{BC}$-free particles. When the critical supersaturation of $\mathrm{BC}$-containing particles is lower (greater) than a given air supersaturation, these particles are defined as hydrophilic (hydrophobic) BC, namely CCN (non$\mathrm{CCN}$ ). By estimating the $\mathrm{CCN}$ activity of $\mathrm{BC}$-containing particles for the entire $\mathrm{BC}$ mixing state (i.e., each grid cell in the 2-D aerosol representation), MADRID-BC can calculate mass concentrations of hydrophobic BC and hydrophilic BC for an air parcel at a given supersaturation (Oshima et al., 2009b).

\subsection{Calculation of conversion rate $\left(1 / \tau_{\mathrm{BC}}\right)$}

The conversion rate of $\mathrm{BC}$ particles from hydrophobic to hydrophilic states due to condensation was estimated for 
Table 1. Summary of all initial parameters used in the calculations.*

\begin{tabular}{ll}
\hline Species & Values \\
\hline $\mathrm{BC}, \mu \mathrm{g} \mathrm{m}^{-3}$ & $0.1,0.5,1.0,5.0,10.0$ \\
$\mathrm{SO}_{2}, \mathrm{ppbv}$ & $0.1,0.5,1.0,5.0,10.0$ \\
$\mathrm{NO}_{\mathrm{x}}, \mathrm{ppbv}$ & $0.1,1.0,10.0$ \\
$\mathrm{NH}_{3}, \mathrm{ppbv}$ & $0.1,1.0,10.0$ \\
$T, \mathrm{~K}$ & 278,298 \\
$\mathrm{RH}, \%$ & $25,35,45,55,65,75,85,95$ \\
\hline
\end{tabular}

* To reduce the number of calculations, we only used combinations of $\mathrm{NO}_{\mathrm{x}}$ and $\mathrm{NH}_{3}$ values $\left(\mathrm{NO}_{\mathrm{x}}, \mathrm{NH}_{3}\right)$ of $(0.1$, $0.1),(0.1,10.0),(1.0,1.0),(10.0,0.1)$, and $(10.0,10.0)$ with combinations of all the other parameters. A total of 48000 calculations, namely $5(\mathrm{BC}) \times 5\left(\mathrm{SO}_{2}\right) \times 5\left(\mathrm{NO}_{\mathrm{x}}\right.$ and $\left.\mathrm{NH}_{3}\right) \times$ $2(T) \times 8(\mathrm{RH}) \times 24$ (hourly photolysis rates), were conducted for a given $\mathrm{BC}$ size distribution.

various atmospheric conditions, from polluted to clean air, using the MADRID-BC model with numerous initial conditions. Because MADRID-BC calculates mass concentrations of condensed materials (e.g., $\mathrm{SO}_{4}^{2-}$ and $\mathrm{NO}_{3}^{-}$) onto $\mathrm{BC}$ particles and $\mathrm{BC}$-free particles from their precursor gases (e.g., $\mathrm{H}_{2} \mathrm{SO}_{4}$ and nitrate acid $\left(\mathrm{HNO}_{3}\right)$, principally produced from the oxidation of $\mathrm{SO}_{2}$ and nitrogen oxides $\left(\mathrm{NO}_{\mathrm{x}}\right)$, respectively), we used several combinations of initial concentrations of $\mathrm{SO}_{2}, \mathrm{NO}_{\mathrm{x}}$, and ammonia $\left(\mathrm{NH}_{3}\right)$ for several combinations of initial values of $\mathrm{BC}$ mass concentration, $T$, and $\mathrm{RH}$. Table 1 shows a summary of all the initial parameters used in the MADRID-BC calculations. Note that these initial parameters cover concentrations of chemical species from polluted urban air (e.g., $\mathrm{BC}=10.0 \mu \mathrm{g} \mathrm{m}^{-3}$ and $\mathrm{SO}_{2}=10.0$ parts per billion by volume (ppbv) at the surface in Beijing; Han et al., 2009; Takegawa et al., 2009) to free tropospheric air (e.g., $\mathrm{BC}=0.1 \mu \mathrm{g} \mathrm{m}^{-3}$ and $\mathrm{SO}_{2}=0.1 \mathrm{ppbv}$ in the free troposphere over the western Pacific; Russo et al., 2003; Oshima et al., 2012). The calculations were conducted using hourly photolysis rates for equinox at midlatitudes, although results obtained in this study can be applied irrespective of latitude and season (see Sects. 3 and 5). The size distribution of the bare BC particles was represented by a lognormal distribution, which was divided into 40 size sections ranging from $0.0215 \mu \mathrm{m}$ to $10 \mu \mathrm{m}$ in MADRID-BC. Mass median diameters $\left(D_{\mathrm{m}}\right)$ and geometric standard deviations $(\sigma)$ of the bare $\mathrm{BC}$ particles were chosen within ranges of those observed in the atmosphere (Kondo et al., 2006; Moteki et al., 2007; Schwarz et al., 2008a, b); namely combinations of $D_{\mathrm{m}}(100$, $125,150,175$, and $200 \mathrm{~nm})$ and $\sigma(1.5$ and 1.8$)$ values were used in this study (Fig. 1). An air supersaturation of $0.1 \%$ was chosen for the definition of hydrophobic BC and hydrophilic BC, because this value is reported as the median value of the measurements under ambient conditions in the literature (Seinfeld and Pandis, 2006), although the ambient supersaturation in clouds varies depending on the cloud dynamics (e.g., updraft velocities) and on the aerosol microphysics (e.g., Koike et al., 2012). The dependence of the

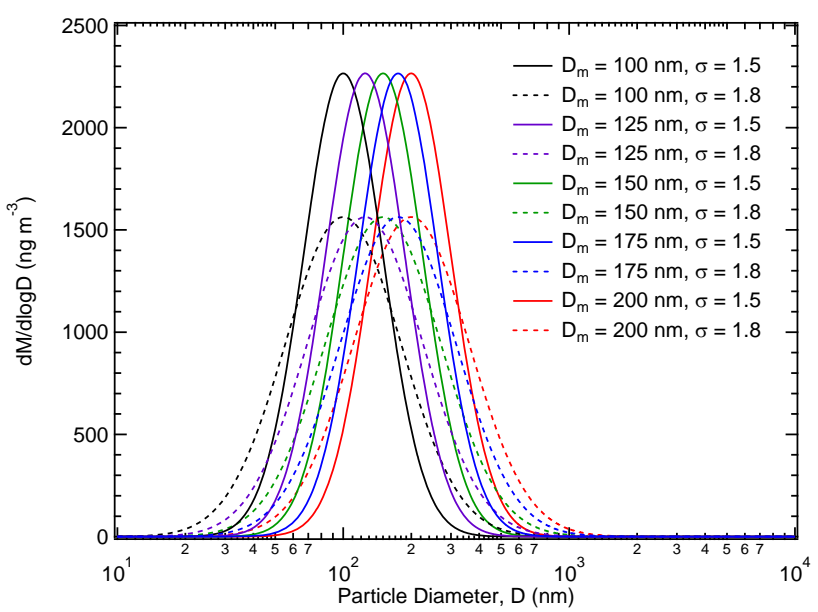

Fig. 1. Mass size distributions of bare BC particles used in this study. Black, purple, green, blue, and red denote mass median diameters $\left(D_{\mathrm{m}}\right)$ of $100,125,150,175$, and $200 \mathrm{~nm}$, respectively. Solid and dashed lines denote geometric standard deviations $(\sigma)$ of 1.5 and 1.8, respectively. The size distributions are shown for a mass concentration of BC particles of $1.0 \mu \mathrm{g} \mathrm{m}^{-3}$ as an example.

conversion rate on the definitions of hydrophobic BC and hydrophilic BC is presented in Appendix B.

In this study, the conversion rate of $\mathrm{BC}$ particles from hydrophobic $\mathrm{BC}$ to hydrophilic $\mathrm{BC}$ is defined as the inverse of the time required for the hydrophobic $\mathrm{BC}$ mass concentration to decay to $1 / e$ of its initial value for each calculation (i.e., $1 / \tau_{\mathrm{BC}}$ ) when only condensational growth takes place. We also define that hydrophobic BC particles are initially bare, and therefore $\tau_{\mathrm{BC}}$ is considered to be the characteristic time required for freshly emitted $\mathrm{BC}$ particles to become $\mathrm{CCN}$ active. Based on this definition, we calculated the time evolutions of increasing coating amounts on bare BC particles due to condensation for each size bin in MADRIDBC. Considering the typical time steps of instantaneous conversion rates used in GCMs, the MADRID-BC calculations were conducted for one hour for each initial condition, and growth rates of coating amounts on bare BC particles (i.e., mass concentration per hour) were estimated for each size bin. By extrapolating the growth rates of coating amounts linearly for all size bins, we calculated the time evolution of coating amounts on the particles and estimated the time duration (i.e., $\tau_{\mathrm{BC}}$ ) when the hydrophobic $\mathrm{BC}$ mass concentration decayed to $1 / e$ of its initial value. These calculations were conducted for the individual initial conditions listed in Table 1 and the individual size distributions ( $D_{\mathrm{m}}$ and $\sigma$ ) shown in Fig. 1 with the individual hourly photolysis rates. A total of 48000 calculations were conducted for a given $\mathrm{BC}$ size distribution (see Table 1). 


\section{Parameterization of $\mathrm{BC}$ aging due to condensation}

\subsection{Hydrophobic-BC-mass-normalized coating rate $\left(V_{\mathrm{BC}}\right)$}

In this study we introduce a new concept, the hydrophobic$\mathrm{BC}$-mass-normalized coating rate, $V_{\mathrm{BC}}\left(\mathrm{h}^{-1}\right)$, defined as follows:

$V_{\mathrm{BC}}=\frac{1}{\left[\mathrm{BC}_{\mathrm{phob}}\right]} \frac{\Delta\left[M_{\text {cond. }}^{\mathrm{BCphob}}\right]}{\Delta t}$,

where $\Delta\left[M_{\text {cond. }}^{\mathrm{BCphob}}\right] / \Delta t$ is the increase rate of the total mass concentration of condensed materials onto initially hydrophobic $\mathrm{BC}$ particles for each hour of calculation. Although the $\tau_{\mathrm{BC}}$ value largely varies depending on the atmospheric conditions and the concentrations of chemical species, we find that the variation of $\tau_{\mathrm{BC}}$ is generally captured well by a unique function of $V_{\mathrm{BC}}$ for a given lognormal size distribution of $B C$ particles. Figure 2 shows the variation of $\tau_{\mathrm{BC}}$ as a function of $V_{\mathrm{BC}}$ for all combinations of the initial parameters shown in Table 1 for each given lognormal BC size distribution $\left(D_{\mathrm{m}}\right.$ and $\left.\sigma\right)$ shown in Fig. 1. Note that each data point (i.e., each gray circle) shown in Fig. 2 corresponds to a result from the calculation for each initial condition. For example, Fig. $2 \mathrm{~g}$ shows the results for a lognormal BC size distribution with a $D_{\mathrm{m}}$ of $175 \mathrm{~nm}$ and $\sigma$ of 1.5 , which is almost identical to that observed in outflow from anthropogenic sources in Japan (Moteki et al., 2007; Oshima et al., 2009a). Fitting the results shown in Fig. 2g, we obtain the following relationship between $\tau_{\mathrm{BC}}$ and $V_{\mathrm{BC}}$ (black curve):

$\tau_{\mathrm{BC}}=\frac{a}{V_{\mathrm{BC}}}$,

where $a=0.3746 \pm 0.0004$. This relationship is intuitive; namely, when a large amount of condensable materials is produced for a certain amount of hydrophobic BC particles, the $\mathrm{BC}$ particles are quickly coated with condensed species (i.e., greater $V_{\mathrm{BC}}$ ), and the time required for the conversion from hydrophobic $\mathrm{BC}$ to hydrophilic $\mathrm{BC}$ becomes shorter (i.e., smaller $\tau_{\mathrm{BC}}$ ). It is noted that $V_{\mathrm{BC}}$ is expressed by the total mass concentration of hydrophobic $\mathrm{BC}$ and that of condensed amounts on the $\mathrm{BC}$ particles, although the $\tau_{\mathrm{BC}}$ values shown in Fig. $2 \mathrm{~g}$ are derived from the calculations of growth rates of coating amounts on the $\mathrm{BC}$ particles for each size bin.

The relationship between $\tau_{\mathrm{BC}}$ and $V_{\mathrm{BC}}$ in Eq. (7) indicates that when the total condensed amount on hydrophobic $\mathrm{BC}$ particles is given for a given size distribution of $\mathrm{BC}$ particles, $\tau_{\mathrm{BC}}$ can be uniquely derived as long as the given $\mathrm{BC}$ size distribution is the same. Although variations of $\tau_{\mathrm{BC}}$ can primarily be represented by $V_{\mathrm{BC}}, \tau_{\mathrm{BC}}$ can also change depending on various factors, such as the chemical composition of coating materials. The spread in $\tau_{\mathrm{BC}}$ for individual $V_{\mathrm{BC}}$ values, shown in Fig. $2 \mathrm{~g}$, reflects the differences in the
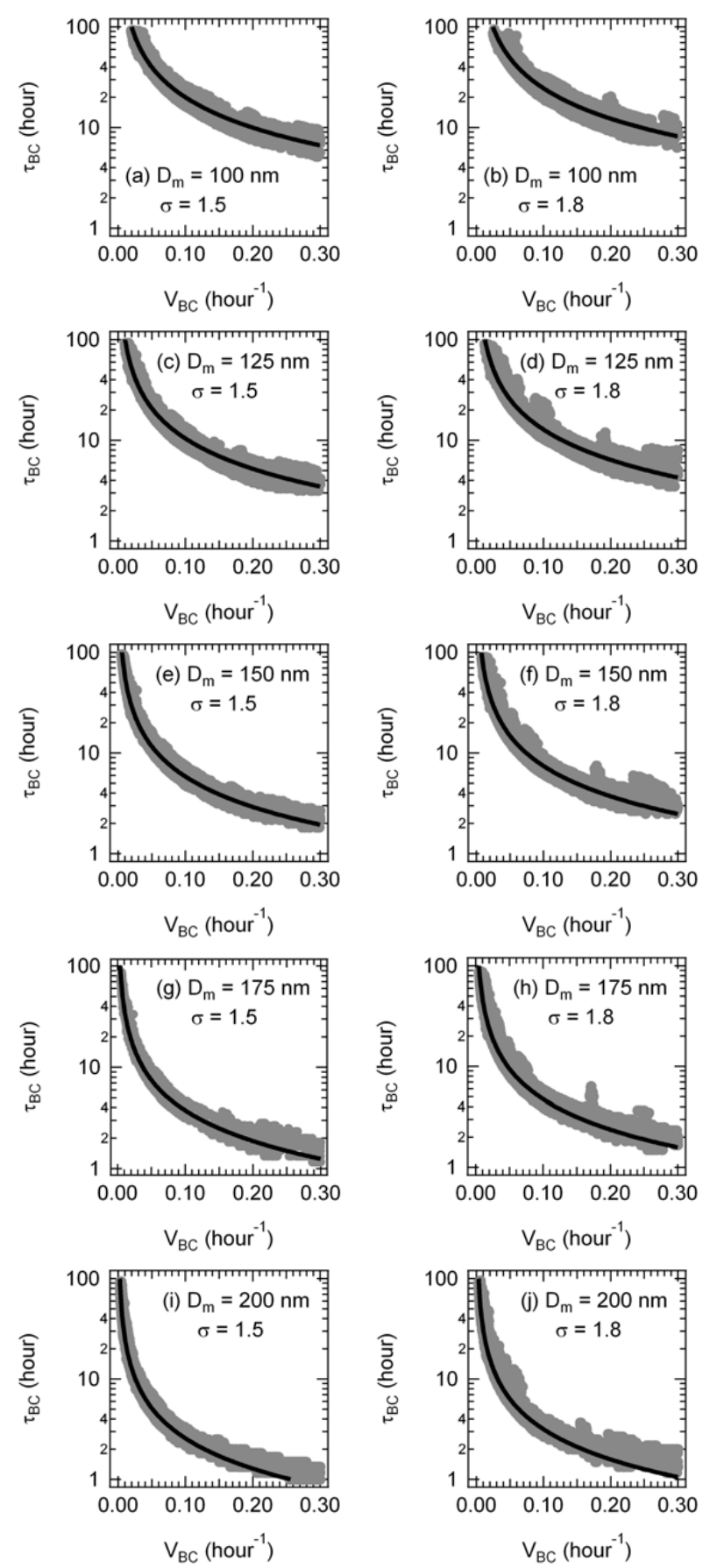

Fig. 2. Relationships between $\tau_{\mathrm{BC}}$ (e-folding time of the conversion from hydrophobic $\mathrm{BC}$ to hydrophilic $\mathrm{BC}$ ) and $V_{\mathrm{BC}}$ (hydrophobicBC-mass-normalized coating rate, defined by Eq. 6) for all combinations of the initial parameters shown in Table 1 for each given lognormal BC size distribution shown in Fig. 1 (gray circles). The black curves show the fitted curve expressed by Eq. (8). 
Table 2. Summary of the $A\left(D_{\mathrm{m}}, \sigma\right)$ values shown in Eq. (8) for combinations of the $D_{\mathrm{m}}$ and $\sigma$ values of hydrophobic BC particles. ${ }^{*}$

\begin{tabular}{lll}
\hline & \multicolumn{2}{c}{$\sigma$} \\
\cline { 2 - 3 }$D_{\mathrm{m}}, \mathrm{nm}$ & 1.5 & 1.8 \\
\hline 100 & 2.00 & 2.45 \\
125 & 1.04 & 1.28 \\
150 & 0.583 & 0.743 \\
175 & 0.375 & 0.474 \\
200 & 0.256 & 0.316 \\
\hline
\end{tabular}

${ }^{*} D_{\mathrm{m}}$ is the mass median diameter

and $\sigma$ is the geometric standard

deviation of a lognormal size

distribution of hydrophobic BC particles.

chemical compositions of coating materials through changes in the atmospheric conditions, which affect the critical supersaturation of particles through the solute effect in Köhler theory.

\subsection{Dependence on size distribution of $\mathrm{BC}$}

Oshima et al. (2009b) showed that the time evolution of the mass fraction of hydrophilic BC particles with respect to total $\mathrm{BC}$ particles due to aging processes depends on the size distribution of initially hydrophobic BC particles. In this section we describe the dependence of $\tau_{\mathrm{BC}}$ on the shape of the lognormal BC size distribution for ranges of $D_{\mathrm{m}}$ of $100-200 \mathrm{~nm}$ and $\sigma$ of $1.5-1.8$ (Fig. 1). We estimated $\tau_{\mathrm{BC}}$ for these lognormal $\mathrm{BC}$ size distributions using the same procedure described in the previous sections. Using the same approach for the Fig. $2 \mathrm{~g}$ case (Sect. 3.1), we obtain the following relationship between $\tau_{\mathrm{BC}}$ and $V_{\mathrm{BC}}$ for any given lognormal $\mathrm{BC}$ size distribution (black curves in Fig. 2):

$\tau_{\mathrm{BC}}=\frac{A\left(D_{\mathrm{m}}, \sigma\right)}{V_{\mathrm{BC}}}$,

where $A\left(D_{\mathrm{m}}, \sigma\right)$ is a constant value representing the dependence on the lognormal BC size distribution. The values of $A\left(D_{\mathrm{m}}, \sigma\right)$ for $D_{\mathrm{m}}$ of $100-200 \mathrm{~nm}$ and $\sigma$ of $1.5-1.8$ are summarized in Table 2 .

According to Eq. (8) and Table 2, the lognormal BC size distribution with the smaller $A\left(D_{\mathrm{m}}, \sigma\right)$ value has the smaller conversion time from hydrophobic BC to hydrophilic $\mathrm{BC}$ (i.e., faster $\mathrm{BC}$ aging). The $A\left(D_{\mathrm{m}}, \sigma\right)$ value decreases with the increase in $D_{\mathrm{m}}$ when the $A\left(D_{\mathrm{m}}, \sigma\right)$ values with the same $\sigma$ are compared (Table 2), because the greater $D_{\mathrm{m}}$ shifts the entire BC size distribution to the larger diameter range (see Fig. 1), and dry particles with larger diameters generally tend to become $\mathrm{CCN}$ active according to Köhler theory (i.e., the maximum of the equilibrium saturation ratio is smaller for the larger particles, and hence they can activate at lower environmental supersaturations). When the $A\left(D_{\mathrm{m}}\right.$, $\sigma)$ values with the same $D_{\mathrm{m}}$ values are compared, the $A\left(D_{\mathrm{m}}\right.$,
1.8) values are greater than the $A\left(D_{\mathrm{m}}, 1.5\right)$ values (Table 2$)$. Because $\tau_{\mathrm{BC}}$ is defined as the time required for the hydrophobic $\mathrm{BC}$ mass concentration to decay to $1 / e$ of its initial value in our calculations and BC-containing particles with greater diameters generally preferentially become $\mathrm{CCN}$ active, the particles greater than the minimum $\mathrm{CCN}$ particle diameter ( $D_{\text {min }}$ ) become CCN active at $\tau_{\mathrm{BC}}$ for a given supersaturation due to $\mathrm{BC}$ aging. The minimum $\mathrm{CCN}$ particle diameter is roughly located where the integral of the size distribution from 0 to $D_{\min }$ equals $1 / e$ of that of the entire size range. Note that $D_{\min }$ is located over the left-hand side of the lognormal size distribution (i.e., range with diameters smaller than $D_{\mathrm{m}}$ ). The greater $\sigma$ value generally distributes BC particles over a wider size range (see Fig. 1) and shifts $D_{\text {min }}$ to smaller diameters (i.e., increase in the number of smaller size BC particles over the left-hand side of the lognormal distribution), and therefore the greater $\sigma$ case needs longer $\tau_{\mathrm{BC}}$ for activation of all particles greater than $D_{\min }$ for a given supersaturation, at least within a range of $D_{\mathrm{m}}$ of $100-200 \mathrm{~nm}$. Large variations in the $A\left(D_{\mathrm{m}}, \sigma\right)$ values, shown in Table 2, indicate the importance of the size distribution of $\mathrm{BC}$ for the $\mathrm{BC}$ aging rate.

\subsection{Formula for the parameterization}

The formula for the parameterized conversion rate from hydrophobic BC to hydrophilic BC due to condensation is represented as follows:

$$
\frac{1}{\tau_{\mathrm{BC}}}=\frac{V_{\mathrm{BC}}}{A\left(D_{\mathrm{m}}, \sigma\right)},
$$

where $V_{\mathrm{BC}}\left(\mathrm{h}^{-1}\right)$ is the hydrophobic-BC-mass-normalized coating rate (given by Eq. 6) and $A\left(D_{\mathrm{m}}, \sigma\right)$ is a constant value representing the dependence on the lognormal $\mathrm{BC}$ size distribution (shown in Table 2). Note that although the $A\left(D_{\mathrm{m}}, \sigma\right)$ values in Eq. (9) depend on the $D_{\mathrm{m}}$ and $\sigma$ values of the size distribution of $\mathrm{BC}$, our parameterization can be used for models that do not explicitly calculate size distributions of aerosols. The $D_{\mathrm{m}}$ and $\sigma$ values can be chosen arbitrarily on the basis of the size distributions of $\mathrm{BC}$ that one wants to assume in models. Because the conversion rate in Eq. (9) is expressed as a function of $V_{\mathrm{BC}}$, which depends on the condensed amount onto the hydrophobic BC particles, the newly developed parameterization can represent large variations of the BC aging rate. Therefore, our parameterization of the conversion rate is a more accurate representation than the constant conversion rates widely used in previous studies. Our parameterization is simple and computationally efficient, allowing its application in GCMs.

It is noted that although we only treat hydrophobic BC as hydrophobic particles in this study, our parameterization is still applicable to $\mathrm{BC}$ particles internally mixed with waterinsoluble particulate organic matter (POM), by replacing the hydrophobic BC mode with a hydrophobic BC/POM mixture mode in models, as long as its size distribution is within 
a range of $D_{\mathrm{m}}$ of $100-200 \mathrm{~nm}$. Note that our parameterization is not applicable to coarse (e.g., dust) particles. In addition, even though our parameterization is derived based on condensation of inorganic species, the relationship in Eq. (9) is applicable to particles including SOAs if values of hygroscopic parameters $(\kappa)$ (e.g., Petters and Kreidenweis, 2007) for water-soluble organic and inorganic species are similar (i.e., the CCN activities of those particles are similar). Our parameterization is also applicable to models that have several aerosol modes other than hydrophobic BC and hydrophilic BC modes, because the conversion rate is derived according to the condensed amounts onto the hydrophobic $\mathrm{BC}$ mode. The presence of other aerosol modes changes the condensed amounts onto the hydrophobic BC mode (i.e., $V_{\mathrm{BC}}$ ) but does not affect the formula in Eq. (9) (see Sect. 4). It is also noted that although we conducted the MADRID-BC calculations for one hour for each initial condition (Sect. 2), additional MADRID-BC calculations with different time durations (e.g., one minute) give the same relationship shown in Eq. (9), supporting the validity of Eq. (9) for use in GCMs with any time steps.

\section{Application of parameterization to GCMs}

In this section, we describe an application method of our parameterization to GCMs, as illustrated in Fig. 3. Our parameterization is applicable to models that do not explicitly treat aerosol microphysics (i.e., do not need explicit calculations of size distributions of aerosols), but it requires the separate treatment of hydrophobic BC and hydrophilic BC modes and the calculations of condensation of bulk amounts of aerosols (at least sulfate aerosols) in models.

Step 1 . The $A\left(D_{\mathrm{m}}, \sigma\right)$ value is taken from Table 2, based on the size distribution of the hydrophobic $\mathrm{BC}$ mode that the user wants to assume in the GCM.

Step 2. To derive the $V_{\mathrm{BC}}$ value by Eq. (6) at each time step in the GCM, the user needs to derive condensed amounts distributed over the hydrophobic BC mode (i.e., $\left.\Delta\left[M_{\text {cond. }}^{\mathrm{BCphob}}\right] / \Delta t\right)$. If the model explicitly calculates the condensed amounts onto the hydrophobic BC mode, the user can directly derive $\Delta\left[M_{\text {cond. }}^{\mathrm{BCphob}}\right] / \Delta t$. If the model does not calculate the condensed amounts, the user may use the following weighting factors, $W_{i}$, for each aerosol mode $i$ (Pandis et al., 1993; Capaldo et al., 2000):

$W_{i}=\frac{N_{i} D_{p, i}}{\frac{2 \lambda_{\mathrm{m}}}{\alpha_{i} D_{p, i}}+1}$,

where $N_{i}$ is the number concentration of particles in mode $i$, $D_{p, i}$ is the mode diameter of the particles in mode $i, \lambda_{\mathrm{m}}$ is the air mean free path, and $\alpha_{i}$ is the accommodation coefficient in mode $i$ on the atmospheric aerosol. These weighting factors are normalized and then used to partition condensable materials, which are produced at each time step, among the aerosol modes, and thus $\Delta\left[M_{\text {cond. }}^{\mathrm{BCphob}}\right] / \Delta t$ is derived.
Step 3. The conversion rate, $1 / \tau_{\mathrm{BC}}$, is calculated using Eq. (9) at each time step in the GCM. Alternatively, the user can choose other representations of our parameterizations that include the coagulation effects on $\mathrm{BC}$ aging (see Sect. 6).

Step 4. Finally, a portion of the BC particles in the hydrophobic $\mathrm{BC}$ mode is converted to the hydrophilic $\mathrm{BC}$ mode using Eqs. (1) and (2). Note that the derived condensed amounts onto the hydrophobic BC mode (i.e., $\left[M_{\text {cond. }}^{\mathrm{BC} \text { phob }}\right]$ ) have to move to the hydrophilic $\mathrm{BC}$ mode (or other internally mixed modes) together with the conversion of the hydrophobic BC particles, because the array of the hydrophobic BC mode may not be allowed to have the condensed amounts (i.e., coatings) in the model.

It is noted that models using the bulk methods generally assume external mixtures for aerosol representations, and therefore they may not treat the internally mixed hydrophilic BC (e.g., BC/sulfate mixture) mode. The difference in the representations of the mixing state of $\mathrm{BC}$ in models can significantly impact estimates of aerosol radiative forcing (e.g., Jacobson, 2001a). Because our parameterization can derive the condensed amount onto the hydrophobic BC mode (i.e., $\left.\left[M_{\text {cond. }}^{\text {BCphob }}\right]\right)$ from the bulk amounts of aerosols together with the conversion rate (see Steps 2 and 4), the use of our parameterization enables representation of the internally mixed hydrophilic BC mode in models that treat aerosols with the bulk method (e.g., Goto et al., 2012).

We describe here several limitations of our parameterization. First, the coagulation effects on the $\mathrm{BC}$ aging are not included in Eq. (9), which can cause errors in the estimation of the conversion rates. Use of Eq. (9) can give conversion rates smaller by approximately $50 \%$ and $10 \%$ due to neglect of the coagulation effects over polluted source regions and outside those regions, respectively, when all initially emitted $\mathrm{BC}$ particles are assumed to be hydrophobic BC (see Appendix A). Because coagulation plays an important role for $\mathrm{BC}$ aging especially over the source regions, we propose other formulations of parameterization of $\mathrm{BC}$ aging including the coagulation effects in Sect. 6. Second, the use of our parameterization with a constant size distribution of hydrophobic BC (i.e., $D_{\mathrm{m}}$ and $\sigma$ ) in models tends to give smaller conversion rates than those in the real atmosphere. This is because the hydrophobic $\mathrm{BC}$ particles are assumed to be uncoated with water-soluble compounds at the end of each time step, and their sizes do not become greater than their initial sizes even after condensation takes place. The use of different size distributions of hydrophobic $\mathrm{BC}$ that depend on the degree of $\mathrm{BC}$ aging (e.g., smaller and greater size distributions of hydrophobic BC over source and remote regions, respectively) may partly reduce the above uncertainties, although their sizes are chosen arbitrarily in this approach. Third, our parameterization cannot represent evaporation effects of aerosols, because the conversion rate is always positive. Finally, large uncertainties in calculating production 


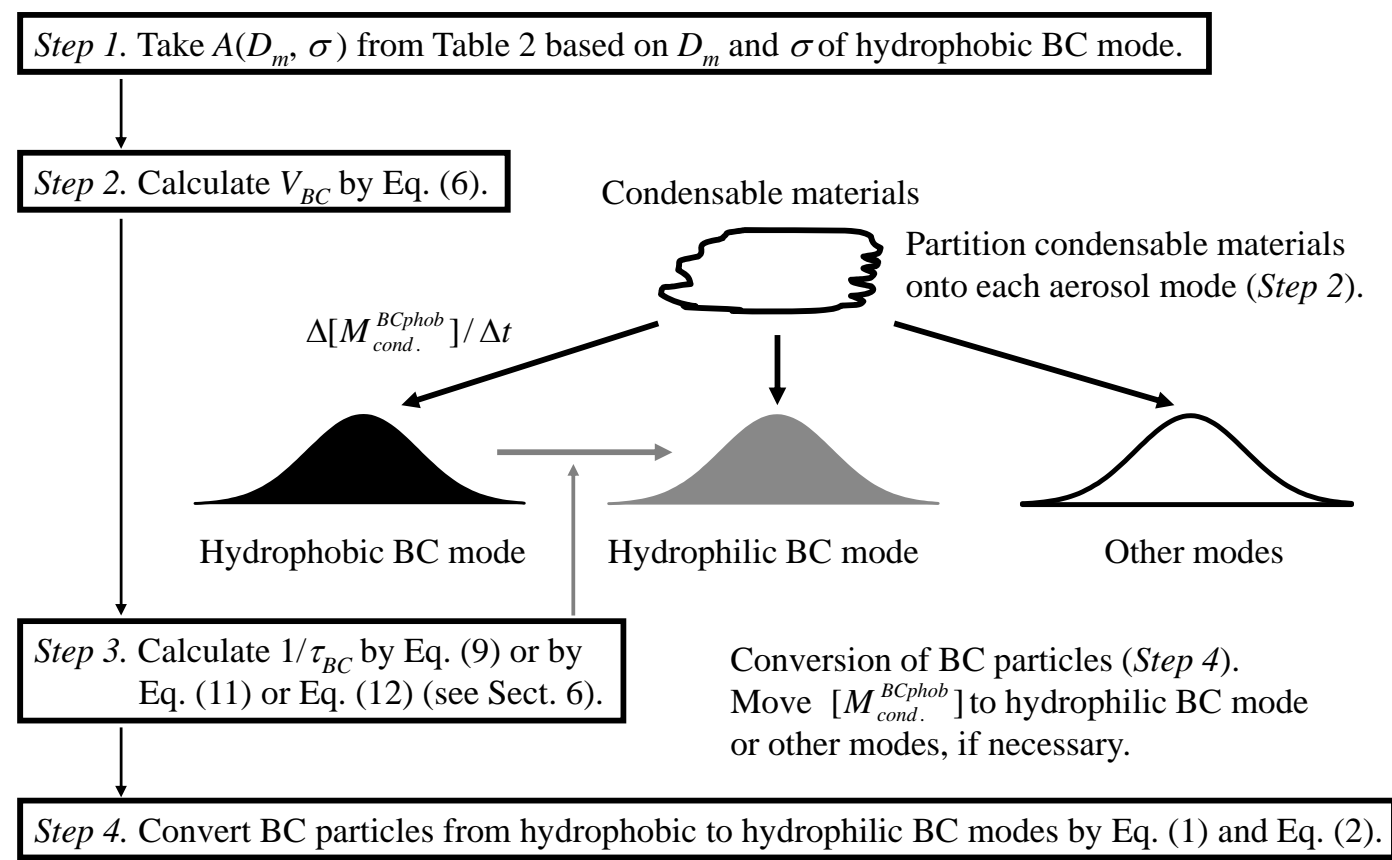

Fig. 3. Schematic diagram of an application method of the parameterization developed in this study to GCMs.

rates of the condensed materials, such as SOAs, in models can lead to errors in the estimation of the conversion rates.

\section{Variations of $\tau_{\mathrm{BC}}$ and $V_{\mathrm{BC}}$}

Our parameterization can represent diurnal and seasonal variations of the $\mathrm{BC}$ aging rate (i.e., conversion rate, $1 / \tau_{\mathrm{BC}}$ ) and its spatial variations through changes in the $V_{\mathrm{BC}}$ values. Some examples of these variations of $\tau_{\mathrm{BC}}$ and the corresponding $V_{\mathrm{BC}}$ values for several initial conditions shown in Table 1 are presented for the lognormal BC size distribution with a $D_{\mathrm{m}}$ of $175 \mathrm{~nm}$ and $\sigma$ of 1.5 in this section.

Figures $4 \mathrm{a}$ and $\mathrm{b}$ show temporal variations of $\tau_{\mathrm{BC}}$ as a function of the initial $\mathrm{SO}_{2}$ concentration for given initial $\mathrm{BC}$, $\mathrm{NO}_{\mathrm{x}}$, and $\mathrm{NH}_{3}$ concentrations for a $T$ of $298 \mathrm{~K}$ and $\mathrm{RH}$ of $45 \%$ and those of $278 \mathrm{~K}$ and $95 \%$, respectively. A detailed description of the initial conditions of the chemical species is given in the figure caption. Figures $4 \mathrm{c}$ and $\mathrm{d}$ show the corresponding $V_{\mathrm{BC}}$ values for each $\tau_{\mathrm{BC}}$ value shown in Figs. $4 \mathrm{a}$ and $b$, respectively. Note that each $\tau_{\mathrm{BC}}$ value (i.e., colored squares shown in Fig. 4) corresponds to the results of calculations for each initial condition. For the high $T$ and low $\mathrm{RH}$ condition (Fig. 4a), BC aging is fast during daytime, with a minimum value of $\tau_{\mathrm{BC}}$ at noontime (e.g., $\tau_{\mathrm{BC}}$ is $6.5 \mathrm{~h}$ for $\mathrm{SO}_{2}$ of $5.0 \mathrm{ppbv}$ at noontime) due to condensation of $\mathrm{H}_{2} \mathrm{SO}_{4}$, produced from the oxidation of $\mathrm{SO}_{2}$ by $\mathrm{OH}$ radical; however, there is no $\mathrm{BC}$ aging during nighttime. This result indicates that $\tau_{\mathrm{BC}}$ clearly has temporal variations and dependencies on the production of $\mathrm{H}_{2} \mathrm{SO}_{4}$ directly and $\mathrm{OH}$ radical indirectly, as presented by previous studies (e.g., Koch, 2001; Wilson et al., 2001; Riemer et al., 2004; Liu et al., 2011). On the other hand, for the low $T$ and high RH condition (Fig. 4b), $\mathrm{BC}$ aging is systematically faster (e.g., $\tau_{\mathrm{BC}}$ is $2.5 \mathrm{~h}$ for $\mathrm{SO}_{2}$ of $5.0 \mathrm{ppbv}$ at noontime) than the high $T$ and low RH condition (Fig. 4a) during daytime due to condensation of both $\mathrm{H}_{2} \mathrm{SO}_{4}$ and $\mathrm{HNO}_{3}$, produced from the oxidation of nitrogen dioxide $\left(\mathrm{NO}_{2}\right)$ by $\mathrm{OH}$ radical, and there is relatively slow $\mathrm{BC}$ aging during nighttime (e.g., $\tau_{\mathrm{BC}}$ is about $13 \mathrm{~h}$ for any $\mathrm{SO}_{2}$ concentration) due to condensation of $\mathrm{HNO}_{3}$, produced from the heterogeneous hydrolysis of dinitrogen pentoxide $\left(\mathrm{N}_{2} \mathrm{O}_{5}\right)$, which occurs in aerosol particles. This result indicates that the atmospheric conditions, such as $T$ and $\mathrm{RH}$, are important for $\tau_{\mathrm{BC}}$ by changing the chemical compositions of condensed materials on $\mathrm{BC}$ particles.

In order to examine the dependence of $\tau_{\mathrm{BC}}$ on $\mathrm{RH}$ in detail, variations of $\tau_{\mathrm{BC}}$ as functions of both the initial $\mathrm{SO}_{2}$ concentration and $\mathrm{RH}$ for the given initial $\mathrm{BC}, \mathrm{NO}_{\mathrm{x}}$, and $\mathrm{NH}_{3}$ concentrations at $T$ of $278 \mathrm{~K}$ at noontime and corresponding $V_{\mathrm{BC}}$ are shown in Figs. 5a and b, respectively. Figures $5 \mathrm{c}$ and $\mathrm{d}$ show mass fractions of $\mathrm{SO}_{4}^{2-}$ and $\mathrm{NO}_{3}^{-}$in condensed materials (i.e., coatings) on $\mathrm{BC}$ particles, respectively, for each $\tau_{\mathrm{BC}}$ calculation shown in Fig. 5a. When the lower RH $(<60 \%)$ and the higher $\mathrm{RH}(>60 \%)$ conditions are compared, $\tau_{\mathrm{BC}}$ in the lower $\mathrm{RH}$ condition is greater for any given initial $\mathrm{SO}_{2}$ concentration (Fig. 5a), and the dominant condensed material of $\mathrm{BC}$ particles is found to be $\mathrm{SO}_{4}^{2-}$ (about $70 \%$ mass fraction, shown in Fig. 5c). For the higher RH condition, $\tau_{\mathrm{BC}}$ decreases with the increase in $\mathrm{RH}$, because the $\mathrm{NO}_{3}^{-}$amount 

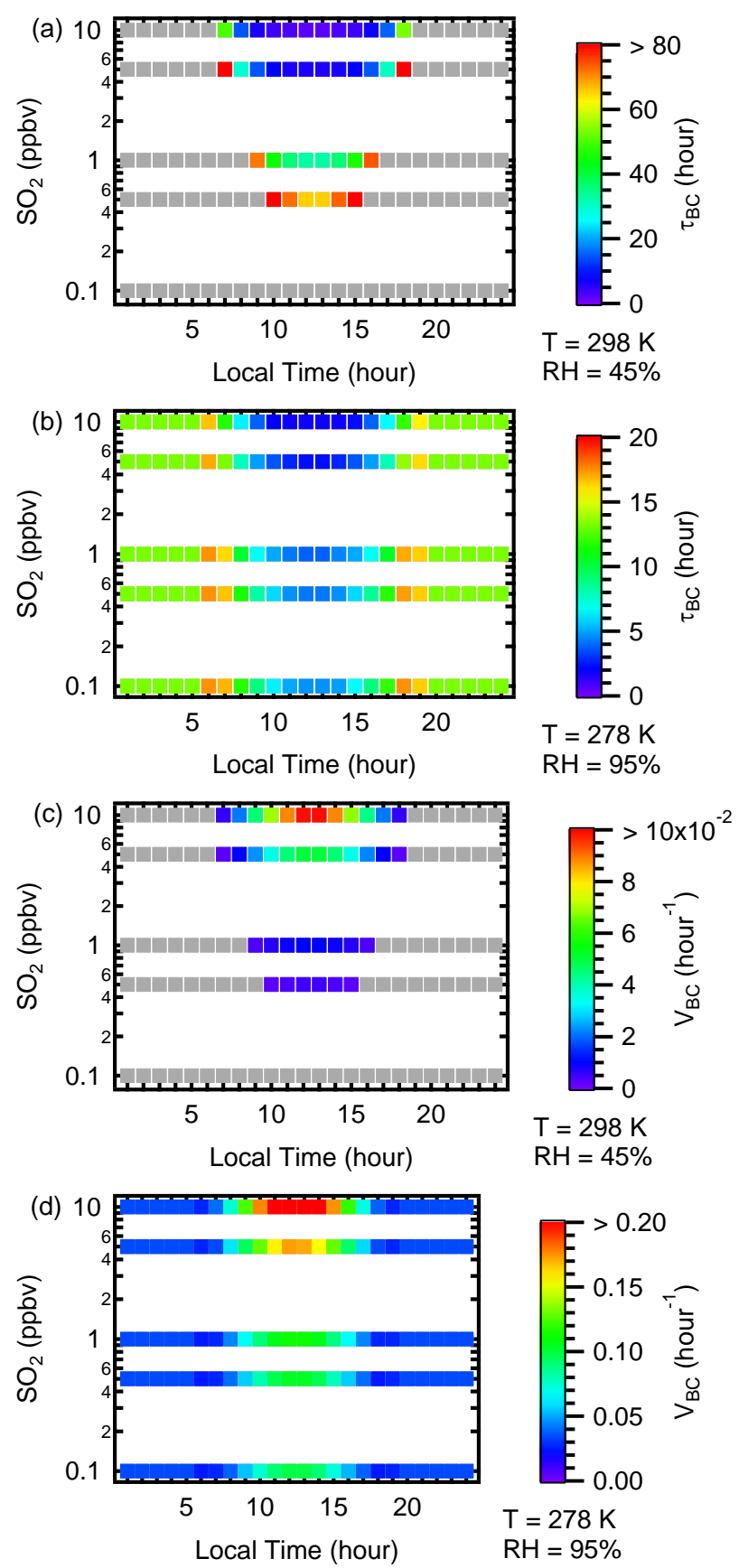

Fig. 4. Temporal variations of (a) $\tau_{\mathrm{BC}}$ and (c) corresponding $V_{\mathrm{BC}}$ for $T$ of $298 \mathrm{~K}$ and $\mathrm{RH}$ of $45 \%$ and (b) $\tau_{\mathrm{BC}}$ and (d) corresponding $V_{\mathrm{BC}}$ for $T$ of $278 \mathrm{~K}$ and $\mathrm{RH}$ of $95 \%$ as a function of the initial $\mathrm{SO}_{2}$ concentration for a given initial $\mathrm{BC}$ mass concentration of $1.0 \mu \mathrm{g} \mathrm{m}^{-3}, \mathrm{NO}_{\mathrm{x}}$ mixing ratio of $1.0 \mathrm{ppbv}$, and $\mathrm{NH}_{3}$ mixing ratio of $1.0 \mathrm{ppbv}$ for the lognormal BC size distribution with a $D_{\mathrm{m}}$ of $175 \mathrm{~nm}$ and $\sigma$ of 1.5 . Note that $\tau_{\mathrm{BC}}$ values greater than $120 \mathrm{~h}$ are indicated in gray.
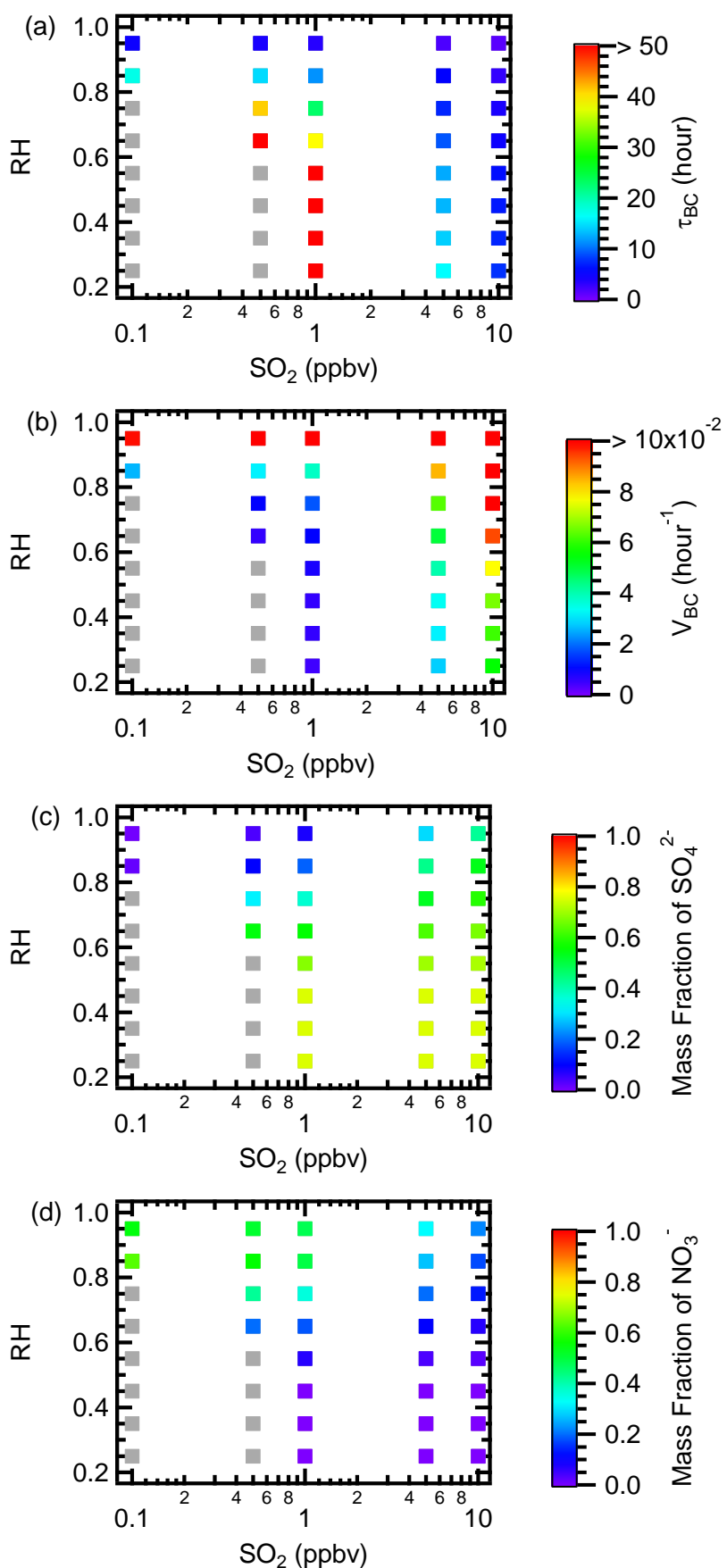

Fig. 5. Variations of (a) $\tau_{\mathrm{BC}}$ and (b) corresponding $V_{\mathrm{BC}}$ as functions of both the initial $\mathrm{SO}_{2}$ concentration and $\mathrm{RH}$ for a given initial $\mathrm{BC}$ mass concentration of $1.0 \mu \mathrm{g} \mathrm{m}^{-3}, \mathrm{NO}_{\mathrm{x}}$ mixing ratio of $1.0 \mathrm{ppbv}$, and $\mathrm{NH}_{3}$ mixing ratio of $1.0 \mathrm{ppbv}$ for a lognormal $\mathrm{BC}$ size distribution with a $D_{\mathrm{m}}$ of $175 \mathrm{~nm}$ and $\sigma$ of 1.5 at $T$ of $278 \mathrm{~K}$ at noontime. Mass fractions of (c) $\mathrm{SO}_{4}^{2-}$ and (d) $\mathrm{NO}_{3}^{-}$in condensed materials on BC particles for each $\tau_{\mathrm{BC}}$ shown in Fig. 5a. Note that $\tau_{\mathrm{BC}}$ values greater than $120 \mathrm{~h}$ are indicated in gray. 

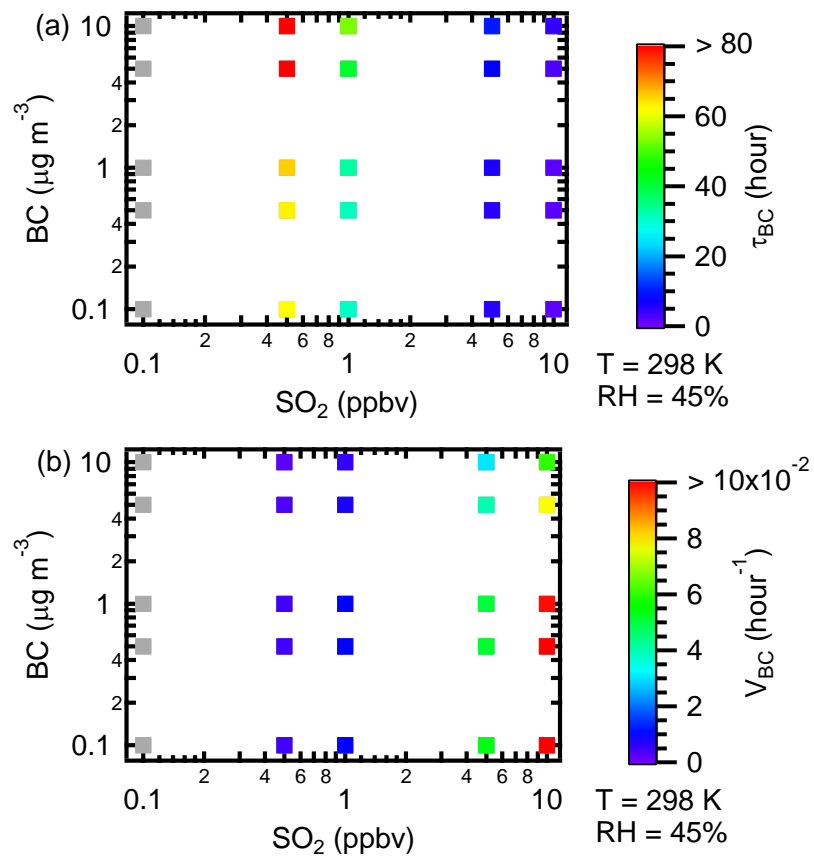

Fig. 6. Variations of (a) $\tau_{\mathrm{BC}}$ and (b) corresponding $V_{\mathrm{BC}}$ as functions of both the initial $\mathrm{SO}_{2}$ concentration and $\mathrm{BC}$ mass concentration for a given initial $\mathrm{NO}_{\mathrm{x}}$ mixing ratio of $1.0 \mathrm{ppbv}$ and $\mathrm{NH}_{3}$ mixing ratio of $1.0 \mathrm{ppbv}$ for the lognormal BC size distribution with a $D_{\mathrm{m}}$ of $175 \mathrm{~nm}$ and $\sigma$ of 1.5 for $T$ of $298 \mathrm{~K}$ and $\mathrm{RH}$ of $45 \%$ at noontime. Note that $\tau_{\mathrm{BC}}$ values greater than $120 \mathrm{~h}$ are indicated in gray.

in condensed materials generally increases with the increase in $\mathrm{RH}$ in addition to $\mathrm{SO}_{4}^{2-}$ amount (e.g., the mass fraction of $\mathrm{NO}_{3}^{-}$in condensed materials is about $40-50 \%$ for $\mathrm{SO}_{2}$ of $1.0 \mathrm{ppbv}$ at RH of 75-95\%, shown in Fig. 5d). This result suggests the importance of nitrate aerosols for the aging and the CCN activity of BC particles especially in uplifting air parcels over anthropogenic source regions, because the upward transport of the air parcels is generally associated with high $\mathrm{RH}$ conditions.

Figures $6 \mathrm{a}$ and $\mathrm{b}$ show variations of $\tau_{\mathrm{BC}}$ and corresponding $V_{\mathrm{BC}}$, respectively, as functions of both the initial $\mathrm{SO}_{2}$ concentration and $\mathrm{BC}$ mass concentration for given initial $\mathrm{NO}_{\mathrm{x}}$ and $\mathrm{NH}_{3}$ concentrations for $T$ of $298 \mathrm{~K}$ and $\mathrm{RH}$ of $45 \%$ at noontime. $\tau_{\mathrm{BC}}$ depends on the ratio of the $\mathrm{SO}_{2}$ and $\mathrm{BC}$ values, indicating that spatial distributions of emission ratios of precursors of condensable materials to $\mathrm{BC}$ (e.g., $\mathrm{SO}_{2} / \mathrm{BC}$ ratio) play important roles for the $\mathrm{BC}$ aging rate.

It is noted that the inverse relationship between $V_{\mathrm{BC}}$ and $\tau_{\mathrm{BC}}$, presented in Sect. 3, can also be seen in Figs. 4, 5, and 6. For example, as shown in Fig. 6, $\tau_{\mathrm{BC}}$ decreases and $V_{\mathrm{BC}}$ increases with the increase in the initial $\mathrm{SO}_{2}$ concentration for any given initial $\mathrm{BC}$ mass concentrations, because the greater initial concentration of precursors (i.e., $\mathrm{SO}_{2}$ ) produces greater condensable materials (i.e., $\mathrm{H}_{2} \mathrm{SO}_{4}$ ) onto the given hydrophobic $\mathrm{BC}$ particles (i.e., greater $V_{\mathrm{BC}}$ ), resulting in a smaller conversion time from hydrophobic BC to hydrophilic BC (i.e., smaller $\tau_{\mathrm{BC}}$ ). It is also noted that $V_{\mathrm{BC}}$ can represent several dependencies of $\tau_{\mathrm{BC}}$ on the atmospheric conditions and the concentrations of chemical species, as shown in Figs. 4, 5, and 6, through changes in the condensed amounts onto hydrophobic $\mathrm{BC}$. The use of $V_{\mathrm{BC}}$ enables the representation of the temporal and the spatial variations of the $\mathrm{BC}$ aging rate in our parameterization.

\section{Parameterization of $\mathrm{BC}$ aging including coagulation effects}

The parameterization of BC aging shown in Eq. (9) only includes condensation effects and does not take in to account coagulation. In this section, we provide two representations of a parameterization including both condensation and coagulation effects (i.e., Eqs. 11 and 12), on the basis of the estimates of the time scale of $\mathrm{BC}$ aging due to coagulation described in Appendix A. The first representation of the parameterization, which uses a constant conversion rate due to coagulation, is expressed as

$\frac{1}{\tau_{\mathrm{BC}}}=\frac{V_{\mathrm{BC}}}{A\left(D_{\mathrm{m}}, \sigma\right)}+\delta$,

where the first term on the right-hand side is the condensation term (i.e., same as the right-hand side of Eq. 9) and $\delta$ is the coagulation term with a constant conversion rate. One may use a conversion time of 20 days for $\delta$ to represent the slow aging outside $\mathrm{BC}$ source regions. In this case, it is recommended to make a suitable assumption regarding the mixing state of $\mathrm{BC}$ upon emission; namely some fraction of BC is emitted as hydrophilic BC (e.g., $80 \%$ hydrophobic and $20 \%$ hydrophilic) to represent the fast aging over the $\mathrm{BC}$ source regions. Because the $\mathrm{BC}$ aging due to coagulation proceeds efficiently over the source regions, the coagulation effect can be treated implicitly in the emission process (see Appendix A). These values (i.e., hydrophilic fraction of $20 \%$ and a conversion time of 20 days) are considered to be more or less reasonable to represent coagulation effects over the source regions and outside those regions, as described in Appendix A.

An alternative representation of the parameterization expresses the coagulation effects as a function of the mass concentration of soluble aerosols as follows:

$$
\frac{1}{\tau_{\mathrm{BC}}}=\frac{V_{\mathrm{BC}}}{A\left(D_{\mathrm{m}}, \sigma\right)}+\sum_{j} k_{\mathrm{coag} ., \mathrm{j}}\left[M_{j}\right],
$$

where the first term on the right-hand side is the condensation term (i.e., Eq. 9) and the second term represents the coagulation effects between hydrophobic BC and soluble aerosol mode $j$ (see Eq. A3 in Appendix A). The $k_{\text {coag.,j }}$ value $\left(\mu \mathrm{g}^{-1} \mathrm{~m}^{3} \mathrm{~s}^{-1}\right)$ is a constant coefficient for coagulation between two aerosol size distributions, namely the lognormal 
size distributions ( $D_{\mathrm{m}}$ and $\sigma$ ) of hydrophobic $\mathrm{BC}$ and soluble aerosol mode $j$, and $\left[M_{j}\right]$ is the mass concentration of the soluble aerosol mode $j$. Table 3 summarizes the $k_{\text {coag.j }}$ values for several combinations of the $D_{\mathrm{m}}$ and $\sigma$ values of hydrophobic $\mathrm{BC}$ and the soluble aerosol mode $j$. The summation is over all coagulation effects between hydrophobic $\mathrm{BC}$ and several soluble aerosol modes (e.g., several soluble BC-free and hydrophilic BC modes). Note that although the $k_{\text {coag.,j }}$ value depends on the size distributions ( $D_{\mathrm{m}}$ and $\sigma$ ) of hydrophobic BC and the soluble aerosol mode $j$, one need not explicitly calculate the size distributions of aerosols in models and can arbitrarily choose $D_{\mathrm{m}}$ and $\sigma$ values from Table 3 .

It is noted that we focus on condensation and treat coagulation effects additionally in this study, because the representations of the condensation effects are more accurate than those of coagulation in our parameterization. The condensation effects in our parameterization (e.g., Eq. 9) are derived using the results of detailed calculations by the MADRID$\mathrm{BC}$ model. On the other hand, the coagulation effects (e.g., the second term on the right-hand side of Eq. 12) are simply estimated from the instantaneous coagulation rates between hydrophobic BC and soluble aerosols (see Appendix A), because the coagulation process is highly non-linear so that the time scales estimated from detailed box model calculations for a specific time interval may not be the same as those for other time intervals. Nevertheless, Eqs. (11) or (12) is considered to be a more accurate representation than the constant conversion rates widely used in previous studies. The parameterized conversion rates shown in Eqs. (11) and (12) are still simple and computationally efficient, allowing their application in GCMs by replacing Eq. (9) with Eq. (11) or Eq. (12) in Step 3 in Sect. 4.

Our newly developed parameterization (i.e., Eq. 11) has been implemented into a global three-dimensional aerosol transport-radiation model, SPRINTARS (Takemura et al., 2005; Goto et al., 2011a, b) driven by a GCM. The usefulness of our parameterization and impacts of $\mathrm{BC}$ aging processes on the spatial distribution of $\mathrm{BC}$ and aerosol radiative forcing using the SPRINTARS model is presented in a subsequent paper (Goto et al., 2012).

\section{Summary and conclusions}

This study develops a new parameterization of the BC aging process for use in GCMs that separately treat hydrophobic $\mathrm{BC}$ and hydrophilic $\mathrm{BC}$ modes using the bulk method, in which only mass concentrations of aerosols are predicted and their size distributions are not explicitly treated. The rate of $\mathrm{BC}$ aging is expressed by the conversion rate of $\mathrm{BC}$ particles from hydrophobic $\mathrm{BC}$ to hydrophilic $\mathrm{BC}$ modes (i.e., $1 / \tau_{\mathrm{BC}}$ ). We estimate the $\tau_{\mathrm{BC}}$ values due to condensation using results from the MADRID-BC model calculations for several combinations of initial concentrations of chemical species and atmospheric conditions (see Table 1) for several given lognormal size distributions of $\mathrm{BC}$ particles (see Fig. 1). In spite of the large variations in the $\tau_{\mathrm{BC}}$ values depending on the atmospheric conditions and the concentrations of chemical species, we find that the variation of $\tau_{\mathrm{BC}}$ is generally captured well by a unique function of $V_{\mathrm{BC}}$ (the hydrophobic-BCmass-normalized coating rate, defined by Eq. 6) for any given lognormal size distributions of BC particles for $D_{\mathrm{m}}$ of 100 $200 \mathrm{~nm}$ and $\sigma$ of 1.5-1.8 (Fig. 1). The parameterized conversion rate from hydrophobic $\mathrm{BC}$ to hydrophilic $\mathrm{BC}$ modes due to condensation is expressed as a function of $V_{\mathrm{BC}}$ with a constant value $A\left(D_{\mathrm{m}}, \sigma\right)$ representing the dependence on the lognormal BC size distribution (listed in Table 2) and is presented in Eq. (9). Alternative representations of the parameterized conversion rates of $\mathrm{BC}$ aging additionally including the coagulation effects are also presented in Eqs. (11) and (12). Our newly developed parameterization can represent diurnal (e.g., faster and slower BC aging during daytime and nighttime, respectively) and seasonal (e.g., faster and slower aging in summer and winter, respectively) variations of the $\mathrm{BC}$ aging rate and its spatial variations (e.g., over source and remote regions) due to changes in the emission ratios of precursors of condensable materials to $\mathrm{BC}$ (e.g., $\mathrm{SO}_{2} / \mathrm{BC}$ and $\mathrm{NO}_{\mathrm{x}} / \mathrm{BC}$ ratios), whereas other widely used constant conversion rates cannot. Use of our parameterization will provide more reliable estimates of the spatial distribution of $\mathrm{BC}$ and its radiative effects in GCMs.

\section{Appendix A}

\section{Estimates of the time scale of $\mathrm{BC}$ aging due to coagulation}

The time scale of $\mathrm{BC}$ aging due to coagulation is estimated in this appendix. The instantaneous coagulation rate $\left(J_{i, j}\right)$ between bare (hydrophobic) BC in size bin $i$ and soluble BCfree particles in size bin $j$ can be expressed using the Fuchs form of the Brownian coagulation coefficient $\left(K_{i, j}\right)$ (Seinfeld and Pandis, 2006):

$J_{i, j}=K_{i, j} N_{\mathrm{BCphob}, i} N_{\mathrm{BCfree}, j}$,

where $N_{\mathrm{BCphob}, i}$ and $N_{\mathrm{BCfree}}, j$ are number concentrations of hydrophobic BC in size bin $i$ and soluble BC-free particles in size bin $j$, respectively. The size distributions of the hydrophobic BC and soluble BC-free particles were represented by lognormal distributions, which were divided into 40 size sections ranging from $0.0215 \mu \mathrm{m}$ to $10 \mu \mathrm{m}$. The instantaneous coagulation rates were calculated for various combinations of the size distributions (mass median diameter $D_{\mathrm{m}}$ and geometric standard deviation $\sigma$ ) of the hydrophobic $\mathrm{BC}$ and soluble $\mathrm{BC}$-free particles and mass concentrations of those particles, as summarized in Table A1. The coagulation between hydrophobic $\mathrm{BC}$ and $\mathrm{BC}$-free particles produces internally mixed $\mathrm{BC}$-containing particles. By estimating 
Table 3. Summary of the $k_{\text {coag.,j }}$ values for several combinations of the $D_{\mathrm{m}}$ and $\sigma$ values of hydrophobic BC and soluble aerosol mode $j$ and the corresponding conversion time of $\mathrm{BC}$ aging due to coagulation over the source regions as examples.*

\begin{tabular}{|c|c|c|c|c|c|c|c|}
\hline \multicolumn{2}{|c|}{ Hydrophobic BC } & \multicolumn{6}{|c|}{ Soluble aerosol mode $j$} \\
\hline \multirow[t]{2}{*}{$\mathrm{D}_{\mathrm{m}}, \mathrm{nm}$} & \multirow[t]{2}{*}{$\sigma$} & \multirow[t]{2}{*}{$\sigma$} & \multicolumn{5}{|c|}{$\mathrm{D}_{\mathrm{m}}, \mathrm{nm}$} \\
\hline & & & 100 & 200 & 300 & 400 & 500 \\
\hline 100 & 1.5 & 1.5 & $8.78(31.6)$ & $18.9(14.7)$ & $11.9(23.3)$ & $6.82(40.7)$ & $4.19(66.2)$ \\
\hline 100 & 1.5 & 1.8 & $9.33(29.9)$ & $14.6(19.0)$ & $11.5(24.1)$ & $8.08(34.4)$ & $5.64(49.3)$ \\
\hline 100 & 1.5 & 2.0 & $9.13(30.8)$ & $12.9(21.6)$ & $10.8(25.7)$ & $8.24(33.7)$ & $6.18(45.0)$ \\
\hline 100 & 1.8 & 1.5 & $10.2(27.1)$ & $22.2(12.5)$ & $14.2(19.6)$ & $8.24(33.7)$ & $5.13(54.2)$ \\
\hline 100 & 1.8 & 1.8 & $10.9(25.6)$ & $17.2(16.1)$ & $13.7(20.3)$ & $9.67(28.7)$ & $6.79(40.9)$ \\
\hline 100 & 1.8 & 2.0 & $10.7(26.3)$ & $15.2(18.3)$ & $12.8(21.6)$ & $9.83(28.3)$ & $7.41(37.5)$ \\
\hline 125 & 1.5 & 1.5 & $7.36(37.8)$ & $15.4(18.1)$ & $9.39(29.6)$ & $5.22(53.3)$ & $3.13(88.7)$ \\
\hline 125 & 1.5 & 1.8 & $7.73(36.1)$ & $11.9(23.4)$ & $9.20(30.2)$ & $6.34(43.8)$ & $4.35(63.8)$ \\
\hline 125 & 1.5 & 2.0 & $7.54(37.4)$ & $10.4(26.6)$ & $8.67(32.1)$ & $6.51(42.7)$ & $4.83(57.5)$ \\
\hline 125 & 1.8 & 1.5 & $8.56(32.5)$ & $18.0(15.4)$ & $11.2(24.8)$ & $6.32(44.0)$ & $3.85(72.2)$ \\
\hline 125 & 1.8 & 1.8 & $9.04(30.9)$ & $14.0(19.9)$ & $10.9(25.5)$ & $7.58(36.6)$ & $5.25(52.9)$ \\
\hline 125 & 1.8 & 2.0 & 8.83 (31.9) & $12.3(22.6)$ & $10.3(27.1)$ & $7.76(35.8)$ & $5.79(48.0)$ \\
\hline 150 & 1.5 & 1.5 & $6.66(41.7)$ & $13.6(20.5)$ & $8.05(34.5)$ & $4.35(63.9)$ & 2.55 (109) \\
\hline 150 & 1.5 & 1.8 & $6.94(40.2)$ & $10.5(26.5)$ & $7.98(34.8)$ & $5.41(51.4)$ & $3.66(75.9)$ \\
\hline 150 & 1.5 & 2.0 & $6.73(41.8)$ & $9.20(30.2)$ & $7.54(36.9)$ & $5.60(49.6)$ & $4.10(67.7)$ \\
\hline 150 & 1.8 & 1.5 & $7.73(36.0)$ & $15.7(17.6)$ & $9.47(29.3)$ & $5.20(53.4)$ & 3.09 (89.8) \\
\hline 150 & 1.8 & 1.8 & $8.11(34.4)$ & $12.2(22.8)$ & $9.34(29.7)$ & $6.39(43.5)$ & $4.36(63.7)$ \\
\hline 150 & 1.8 & 2.0 & $7.93(35.5)$ & $10.7(25.9)$ & $8.83(31.5)$ & $6.59(42.1)$ & $4.86(57.1)$ \\
\hline 175 & 1.5 & 1.5 & $6.32(44.0)$ & $12.6(22.0)$ & $7.29(38.1)$ & $3.83(72.4)$ & $2.20(127)$ \\
\hline 175 & 1.5 & 1.8 & $6.54(42.7)$ & $9.73(28.5)$ & $7.30(38.1)$ & $4.88(56.9)$ & $3.26(85.2)$ \\
\hline 175 & 1.5 & 2.0 & $6.32(44.5)$ & $8.53(32.6)$ & $6.92(40.2)$ & $5.09(54.6)$ & 3.69 (75.2) \\
\hline 175 & 1.8 & 1.5 & $7.43(37.4)$ & $14.5(19.2)$ & $8.46(32.8)$ & $4.52(61.5)$ & $2.63(106)$ \\
\hline 175 & 1.8 & 1.8 & $7.84(35.6)$ & $11.2(24.7)$ & $8.45(32.9)$ & $5.69(48.8)$ & $3.83(72.6)$ \\
\hline 175 & 1.8 & 2.0 & $7.73(36.4)$ & $9.90(28.1)$ & $8.01(34.7)$ & $5.91(47.0)$ & $4.31(64.4)$ \\
\hline 200 & 1.5 & 1.5 & $6.19(44.9)$ & $12.1(22.9)$ & $6.86(40.5)$ & $3.52(78.9)$ & $1.97(141)$ \\
\hline 200 & 1.5 & 1.8 & $6.36(43.9)$ & $9.35(29.7)$ & $6.93(40.1)$ & $4.58(60.7)$ & $3.02(92.1)$ \\
\hline 200 & 1.5 & 2.0 & $6.14(45.9)$ & $8.20(33.9)$ & $6.58(42.2)$ & 4.79 (57.9) & $3.45(80.5)$ \\
\hline 200 & 1.8 & 1.5 & $7.56(36.8)$ & $13.8(20.1)$ & $7.86(35.4)$ & $4.09(67.9)$ & $2.32(120)$ \\
\hline 200 & 1.8 & 1.8 & $8.19(34.1)$ & $10.8(25.8)$ & $7.95(34.9)$ & $5.27(52.7)$ & $3.50(79.4)$ \\
\hline 200 & 1.8 & 2.0 & $8.29(34.0)$ & $9.57(29.0)$ & $7.59(36.6)$ & $5.53(50.3)$ & 3.99 (69.6) \\
\hline
\end{tabular}

${ }^{*} D_{\mathrm{m}}$ is the mass median diameter and $\sigma$ is the geometric standard deviation of lognormal size distributions of hydrophobic BC and soluble aerosol mode $j$ (e.g., BC-free

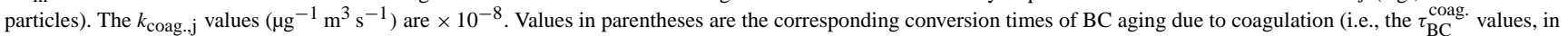
hours) for a mass concentration of soluble aerosol mode $j$ of $100 \mu \mathrm{g} \mathrm{m}^{-3}$ (see Appendix A).

Table A1. Summary of parameters used in the estimation of coagulation effects.*

\begin{tabular}{llll}
\hline Species & $D_{\mathrm{m}}, \mathrm{nm}$ & $\sigma$ & \multicolumn{1}{l}{ Mass concentrations, $\mu \mathrm{g} \mathrm{m}^{-3}$} \\
\hline $\begin{array}{l}\text { Hydrophobic BC } \\
\text { Soluble BC-free }\end{array}$ & $100,125,150,175,200$ & $1.5,1.8$ & $0.1,0.5,1.0,5.0,10.0$ \\
& $100,200,300,400,500$ & $1.5,1.8,2.0$ & $0.1,0.2,0.5,1.0,2.0,5.0,10,20,50,100,200,500$ \\
\hline
\end{tabular}

the $\mathrm{CCN}$ activity of the produced $\mathrm{BC}$-containing particles (Eq. A1) for the entire size range using the Köhler equation (see Sect. 2) and by integrating the total BC mass concentrations in the hydrophilic state, we calculated the instantaneous conversion rate of mass concentration of $\mathrm{BC}$ from hydrophobic to hydrophilic states due to coagulation between the size distributions of hydrophobic BC and soluble $\mathrm{BC}$ free particles $\left(\Delta\left[\mathrm{BC}_{\mathrm{phob}}\right] / \Delta t\right)$. Although the $\Delta\left[B C_{\mathrm{phob}}\right] / \Delta t$ value largely varies depending on the mass concentrations of hydrophobic $\mathrm{BC}\left(\left[\mathrm{BC}_{\mathrm{phob}}\right]\right)$ and soluble $\mathrm{BC}$-free $\left(\left[\mathrm{BC}_{\text {free }}\right]\right)$ particles, the $\Delta\left[\mathrm{BC}_{\mathrm{phob}}\right] / \Delta t$ value can be expressed in terms of $\left[\mathrm{BC}_{\text {phob }}\right]$ and $\left[\mathrm{BC}_{\text {free }}\right]$ with the constant coefficient $k_{\text {coag. }}$ 

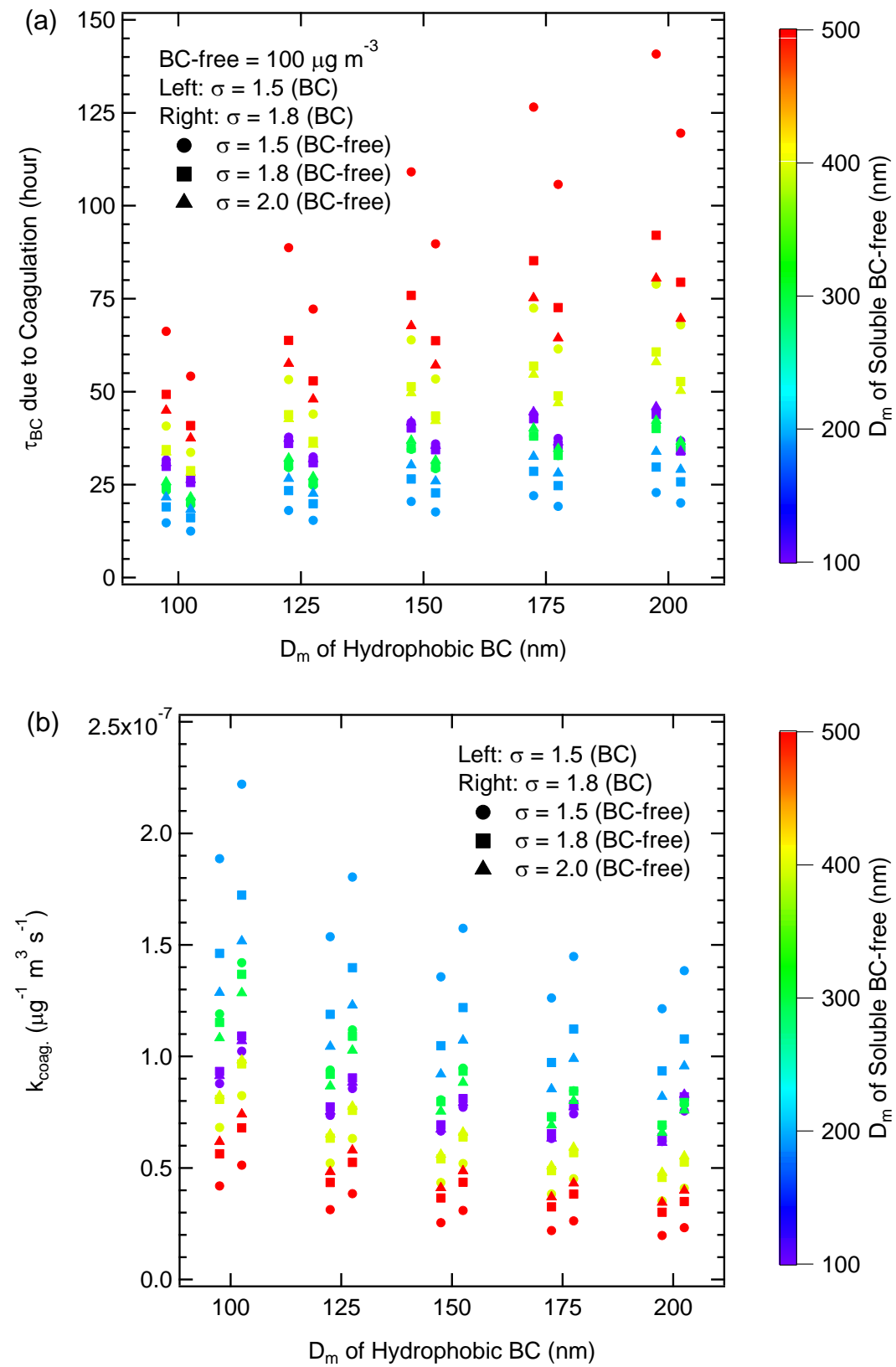

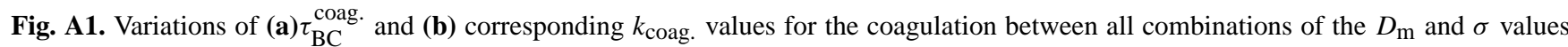

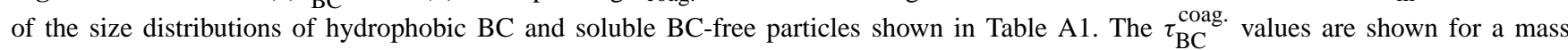
concentration of soluble BC-free particles of $100 \mu \mathrm{g} \mathrm{m}^{-3}$. The left-hand and right-hand sides of each $D_{\mathrm{m}}$ of hydrophobic BC particles denote the values for $\sigma$ of hydrophobic BC particles of 1.5 and 1.8, respectively. Circles, squares, and triangles denote the values for $\sigma$ of soluble BC-free particles of $1.5,1.8$, and 2.0, respectively. Colors indicate the values for $D_{\mathrm{m}}$ of soluble BC-free particles.

$\left(\mu \mathrm{g}^{-1} \mathrm{~m}^{3} \mathrm{~s}^{-1}\right)$, which represents the dependences on the lognormal size distributions ( $D_{\mathrm{m}}$ and $\sigma$ ) of the hydrophobic BC and soluble $\mathrm{BC}$-free particles:

$$
\frac{\Delta\left[\mathrm{BC}_{\mathrm{phob}}\right]}{\Delta t}=-k_{\text {coag. }}\left[\mathrm{BC}_{\text {free }}\right]\left[\mathrm{BC}_{\text {phob }}\right] \text {. }
$$

It is noted that the coefficient $k_{\text {coag. }}$ includes not only the coagulation effects (e.g., $K_{i, j}$ in Eq. A1) but also the mass fraction of hydrophilic $\mathrm{BC}$ with respect to total $\mathrm{BC}$ particles that experiences the coagulation process. Assuming that the $\left[\mathrm{BC}_{\text {free }}\right]$ value is constant and analytically solving Eq. (A2) gives 
Table A2. Summary of the calculations for estimates of errors included in Eq. (9) due to neglect of coagulation effects on BC aging over the source and the outflow regions.*

\begin{tabular}{|c|c|c|c|c|c|c|c|c|c|}
\hline & \multicolumn{3}{|c|}{ Concentration of chemical species } & \multicolumn{2}{|c|}{ Size distribution $\left(D_{\mathrm{m}}, \sigma\right)$} & \multicolumn{3}{|c|}{ Conversion time scale } & \multirow[t]{2}{*}{ Reference } \\
\hline Calculation name & $\mathrm{SO}_{2}, \mathrm{ppbv}$ & $\mathrm{BC}, \mu \mathrm{g} \mathrm{m} \mathrm{m}^{-3}$ & $\begin{array}{l}\text { BC- } \\
\text { free, } \mu g \mathrm{~m}^{-3}\end{array}$ & $\begin{array}{l}\text { Hydrophobic } \\
\text { BC }\end{array}$ & $\begin{array}{l}\text { Soluble } \\
\text { BC-free }\end{array}$ & $\begin{array}{l}\tau_{\mathrm{BC}}^{\text {cond. }}, \\
\text { hour }\end{array}$ & $\begin{array}{l}\tau_{\mathrm{BC}}^{\text {coag. }}, \\
\text { hour }\end{array}$ & $F_{\text {coag. }} \%$ & \\
\hline $\begin{array}{l}\text { Polluted source } \\
\text { (Beijing) }\end{array}$ & 10 & 10 & 100 & $(125,1.5)$ & $(300,2.0)$ & 31.3 & 32.1 & 49.4 & $\begin{array}{l}\text { Takegawa et al. (2009) } \\
\text { Matsui et al. (2009) } \\
\text { Kondo et al. (2006) }\end{array}$ \\
\hline $\begin{array}{l}\text { Source } \\
\text { (Beijing) }\end{array}$ & 10 & 5.0 & 30 & $(125,1.5)$ & $(300,2.0)$ & 13.8 & 107 & 11.4 & \\
\hline $\begin{array}{l}\text { Polluted outflow } \\
\text { (western Pacific) }\end{array}$ & 1.0 & 1.0 & 10 & $(175,1.5)$ & $(300,2.0)$ & 25.2 & 402 & 5.90 & $\begin{array}{l}\text { Moteki et al. (2007) } \\
\text { Oshima et al. (2009a) } \\
\text { Whitby (1978) }\end{array}$ \\
\hline $\begin{array}{l}\text { Outflow } \\
\text { (western Pacific) }\end{array}$ & 0.5 & 0.5 & 5.0 & $(175,1.5)$ & $(300,2.0)$ & 20.1 & 803 & 2.44 & \\
\hline
\end{tabular}

${ }^{*} D_{\mathrm{m}}$ is the mass median diameter and $\sigma$ is the geometric standard deviation of lognormal size distributions of hydrophobic BC and soluble BC-free particles. The $\tau_{\mathrm{BC}}^{\text {cond. }}$ and $\tau_{\mathrm{BC}}^{\text {coag. }}$ values are the conversion time scales from hydrophobic $\mathrm{BC}$ to hydrophilic $\mathrm{BC}$ due to condensation and coagulation, respectively, and these values are estimated by the MADRID-BC model calculations and from Eq. (A3), respectively. $F_{\text {coag }}$ is the contribution of the coagulation effects to the overall conversion rate of $\mathrm{BC}$ aging. Values of the concentrations of chemical species and the size distributions are taken from the corresponding observations (see references in this table).

$\tau_{\mathrm{BC}}^{\text {coag. }}=\frac{1}{k_{\text {coag. }}\left[\mathrm{BC}_{\text {free }}\right]}$,

where $\tau_{\mathrm{BC}}^{\text {coag. }}$ is the characteristic (e-folding) time of the conversion due to the coagulation between the size distributions of hydrophobic BC and soluble BC-free particles. Table 3 summarizes the $k_{\text {coag. }}$ values (the $k_{\text {coag.j.j }}$ values in Table 3) for all combinations of the $D_{\mathrm{m}}$ and $\sigma$ values of hydrophobic BC and soluble BC-free particles (soluble aerosol mode $j$ in Table 3) shown in Table A1. Equation (A3) indicates that $\tau_{\mathrm{BC}}^{\text {coag. }}$ can be estimated from the mass concentration of soluble $\mathrm{BC}$-free particles ( $\left.\left[\mathrm{BC}_{\text {free }}\right]\right)$ using the pre-determined constant coefficient $\left(k_{\text {coag. }}\right)$ for the given lognormal size distributions $\left(D_{\mathrm{m}}\right.$ and $\left.\sigma\right)$ of hydrophobic BC and soluble BCfree particles.

Using Eq. (A3), we estimated the time scales of BC aging due to coagulation (i.e., $\tau_{\mathrm{BC}}^{\text {coag. }}$ ) for polluted source regions and outside those regions. According to Seinfeld and Pandis (2006), typical values of mass concentrations of fine aerosol particles for polluted urban air are $30-150 \mu \mathrm{g} \mathrm{m}^{-3}$. The Campaigns of Air Quality Research in Beijing and Surrounding Region 2006 (CAREBeijing 2006) also showed that the observed mass concentrations of fine aerosol particles were about $30-100 \mu \mathrm{g} \mathrm{m}^{-3}$ on average in the Beijing region (Matsui et al., 2009). Although these mass concentrations included both $\mathrm{BC}$-containing and $\mathrm{BC}$-free particles, we applied these bulk values to mass concentrations of soluble BC-free particles in our estimates. The variations of the $\tau_{\mathrm{BC}}^{\text {coag. }}$ values for coagulation between all combinations of the size distributions (i.e., $D_{\mathrm{m}}$ and $\sigma$ ) of hydrophobic $\mathrm{BC}$ and soluble BC-free particles (shown in Table A1) are shown for a $\left[\mathrm{BC}_{\text {free }}\right]$ of $100 \mu \mathrm{g} \mathrm{m}^{-3}$ in Fig. A1a and Table 3. The cor-

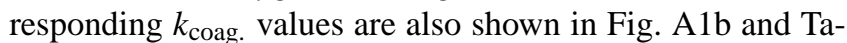
ble 3. As shown in Fig. A1a, the $\tau_{\mathrm{BC}}^{\text {coag. }}$ value largely varies especially depending on the $D_{\mathrm{m}}$ of soluble BC-free and hydrophobic BC particles. Previous studies showed that a size distribution of BC particles with $D_{\mathrm{m}}=125$ and $\sigma=1.5$ was often observed over the urban region in Tokyo (Kondo et al., 2006). For fine aerosol size distributions, values of $D_{\mathrm{m}}=300$ and $\sigma=2.0$ were reported by Whitby (1978) based on nearsource observations (Binkowski and Roselle, 2003). Using these values, the $\tau_{\mathrm{BC}}^{\text {coag. }}$ values are estimated to be $21-107 \mathrm{~h}$ for urban polluted air conditions (i.e., $\left[\mathrm{BC}_{\text {free }}\right]$ range of 30 $150 \mu \mathrm{g} \mathrm{m}^{-3}$ ). For the air outside polluted source regions, assuming a typical mass concentration of fine aerosol particles of $5-10 \mu \mathrm{g} \mathrm{m}^{-3}$, the $\tau_{\mathrm{BC}}^{\text {coag. }}$ values are estimated to be 17-33 days for a size distribution of hydrophobic BC with $D_{\mathrm{m}}=175$ and $\sigma=1.5$ (Moteki et al., 2007; Oshima et al., 2009a) and soluble BC-free particles with $D_{\mathrm{m}}=300$ and $\sigma=2.0$ (Whitby, 1978).

The large difference in the $\tau_{\mathrm{BC}}^{\text {coag. }}$ values for the polluted source regions (i.e., 21-107 h) and outside those regions (i.e., 17-33 days) indicates that the coagulation effects on $\mathrm{BC}$ aging can be treated separately in the parameterized conversion rates from hydrophobic $\mathrm{BC}$ to hydrophilic $\mathrm{BC}$ over those two regions. Considering the $\tau_{\mathrm{BC}}^{\text {coag. }}$ values over the source regions and the time scale over which air parcels are transported outside a source domain in GCMs, the coagulation effects over the source regions can be implicitly treated in the emission process of BC, such as assuming $80 \%$ hydrophobic and $20 \%$ hydrophilic for initially emitted BC particles, which were widely used in previous studies (e.g., Cooke et al., 2002; Chung and Seinfeld, 2005; Donner et al., 2011; Skeie et al., 2011). On the other hand, considering that most domains in GCMs are outside the source regions, the use of a constant conversion time, such as 20 days (i.e., $\delta$ in Eq. 11), is considered to be more or less acceptable for representation of the coagulation effects over those regions. 
We estimated the error included in Eq. (9) due to neglect of coagulation effects on $\mathrm{BC}$ aging. For this purpose, we calculated the conversion time from hydrophobic $\mathrm{BC}$ to hydrophilic $\mathrm{BC}$ due to condensation ( $\tau_{\mathrm{BC}}^{\text {cond. }}$ ) by the MADRID$\mathrm{BC}$ model using the same methods described in Sect. 2 for the source (Beijing) and outflow (western Pacific) regions. Table A2 shows a summary of the parameters used in the MADRID-BC calculations. The concentrations shown in Table $\mathrm{A} 2$ over the source and the outflow regions are taken from the CAREBeijing campaign conducted in the Beijing region and the Pacific Exploration of Asian Continental Emission phase C (PEACE-C) aircraft campaign conducted over the western Pacific around Japan, respectively. Using these values, we calculated the diurnal variations of $\tau_{\mathrm{BC}}^{\text {cond. for the high }}$ $T$ and low RH (i.e., $T=298 \mathrm{~K}$ and $\mathrm{RH}=45 \%$ ) and the low $T$ and high RH (i.e., $T=278 \mathrm{~K}$ and $\mathrm{RH}=95 \%$ ) conditions for each case. By simply averaging the $1 / \tau_{\mathrm{BC}}^{\text {cond. values for }}$ both conditions, the diurnally averaged $\tau_{\mathrm{BC}}^{\text {cond. }}$ values were estimated for each case (Table A2). Comparing the $\tau_{\mathrm{BC}}^{\text {cond. }}$ values with the corresponding $\tau_{\mathrm{BC}}^{\text {coag. }}$ values for each case (estimated from Eq. A3 and shown in Table A2), we estimated contributions of the coagulation effects to the overall conversion rate of $\mathrm{BC}$ aging (see $F_{\text {coag. }}$ in Table A2). The result shown in Table A2 indicates that the conversion rates shown in Eq. (9) can give smaller values by $11-49 \%$ and $2.4-5.9 \%$ over the source and outflow regions, respectively, due to neglect of the coagulation effects. This estimate suggests that the use of Eq. (9) can include approximately $50 \%$ and $10 \%$ errors over the polluted source regions and outside those regions, respectively. Note that the large difference in the error values estimated for the polluted source regions and outside those regions also gives confidence in the validity of our approach to separately treat the coagulation effects on $\mathrm{BC}$ aging in Eq. (11) for those two regions.

\section{Appendix B}

\section{Dependence on definitions of hydrophobic BC and hydrophilic BC}

In this study, an air supersaturation of $0.1 \%$ is used for definitions of hydrophobic $\mathrm{BC}$ and hydrophilic $\mathrm{BC}$ by calculating the $\mathrm{CCN}$ activity of particles using the Köhler equation (Sect. 2). Most GCMs generally define hydrophilic BC as particles experiencing water uptake and wet deposition processes in the model and hydrophobic BC as particles not experiencing these processes. For GCMs that treat aerosols with the bulk method, this classification may only provide arrays of hydrophobic BC and hydrophilic BC in models, and there may not be a clear threshold value to distinguish between hydrophobic and hydrophilic states of BC particles. However, our definition can give the degree of the threshold values between the hydrophobic BC and the hydrophilic BC modes based on supersaturation. It is noted that supersaturation is initially used for the definition of $\mathrm{BC}$ particles in models, and we do not need to calculate supersaturation itself in models (e.g., we do not need to calculate supersaturations for aerosol activation).

In this appendix, we describe the dependence of $\tau_{\mathrm{BC}}$ on the definitions of hydrophobic BC and hydrophilic BC, namely supersaturation, $s(\%)$, between $0.05 \%$ and $1 \%$ for all lognormal BC size distributions shown in Fig. 1. The dependence is expressed by $F(s) \equiv \tau_{\mathrm{BC}}(s) / \tau_{\mathrm{BC}}(0.1)$, where $\tau_{\mathrm{BC}}(s)$ and $\tau_{\mathrm{BC}}(0.1)$ are the $\tau_{\mathrm{BC}}$ values for a supersaturation of any $s \%$ and $0.1 \%$, respectively. $F(s)$ is approximately derived from Köhler theory as follows (see latter half of this appendix):

$F(s) \equiv \frac{\tau_{\mathrm{BC}}(s)}{\tau_{\mathrm{BC}}(0.1)}=\left(\frac{\ln \left(1+\frac{0.1}{100}\right)}{\ln \left(1+\frac{s}{100}\right)}\right)^{2}$.

Figure B1 shows comparisons of the $F(s)$ values as a function of $s$ calculated by Eq. (B1) (black curves) with the $\tau_{\mathrm{BC}}(s) / \tau_{\mathrm{BC}}(0.1)$ values derived from the calculation results using all combinations of the initial parameters (shown in Table 1 ) between $0.05 \%$ and $1 \%$ with a $0.05 \%$ interval (gray circles) for each given lognormal BC size distribution (shown in Fig. 1). The good agreements shown in Fig. B1 indicate the validity of the use of Eq. (B1) to represent the dependence on the supersaturation, at least between $0.05 \%$ and $1 \%$, for the given lognormal BC size distributions shown in Fig. 1.

Taking into account this dependence, a formula for the parameterized conversion rate from hydrophobic BC to hydrophilic BC presented in Eq. (9) is represented as follows:

$$
\frac{1}{\tau_{\mathrm{BC}}}=\frac{V_{\mathrm{BC}}}{A\left(D_{\mathrm{m}}, \sigma\right) \cdot F(s)},
$$

where $V_{\mathrm{BC}}\left(\mathrm{h}^{-1}\right)$ is the hydrophobic-BC-mass-normalized coating rate (given by Eq. 6), $A\left(D_{\mathrm{m}}, \sigma\right)$ is a constant value representing the dependence on the lognormal $\mathrm{BC}$ size distribution (shown in Table 2), and $F(s)$ is a correction factor for the definition of hydrophobic BC and hydrophilic BC (given by Eq. B1).

Finally, an application method of this parameterization (Eq. B2) to GCMs is described here. If the user wants to change the definition of hydrophobic $\mathrm{BC}$ and hydrophilic $\mathrm{BC}$ in the user's GCM, one value of supersaturation, $s \%$, has to be chosen by the user to calculate $F(s)$ using Eq. (B1). For example, if the user wants to give the degrees of hydrophilic particles as those activated for stratiform clouds, the user can give smaller values of $s$, such as $0.05 \%$, for the correction factor $F(s)$. The subsequent method is described in Sect. 4.

In the following, an approach to obtain Eq. (B1) is described. We consider a particle having uniform soluble chemical composition for simplicity. According to the Köhler equation (Seinfeld and Pandis, 2006), the saturation ratio, $S$, at equilibrium over an aqueous solution droplet is expressed as 

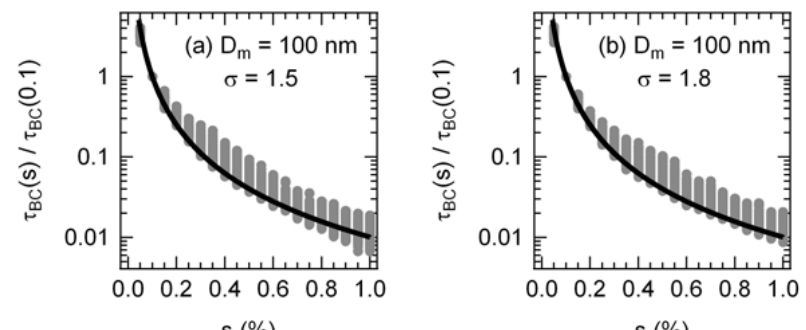

$\mathrm{s}(\%)$
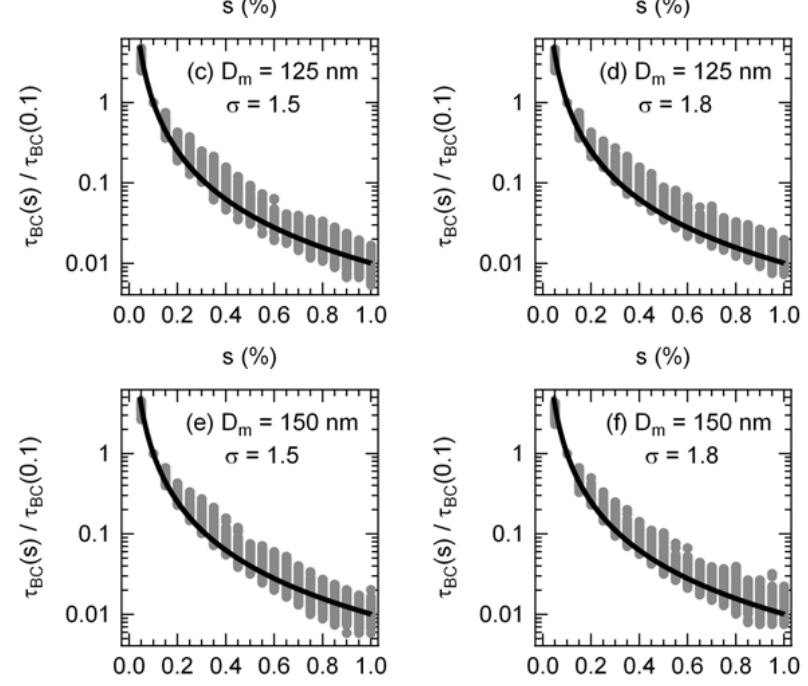

s $(\%)$
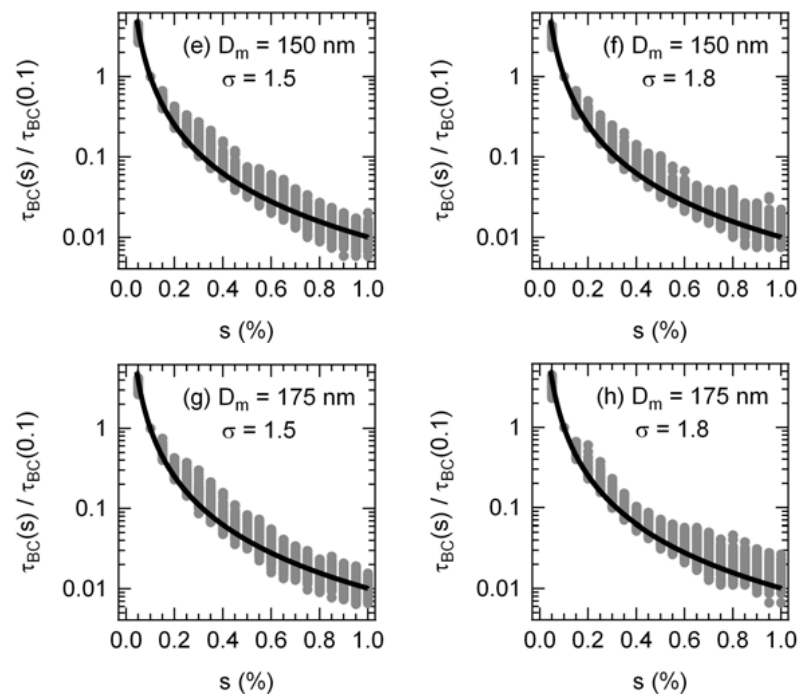

$\mathrm{s}(\%)$
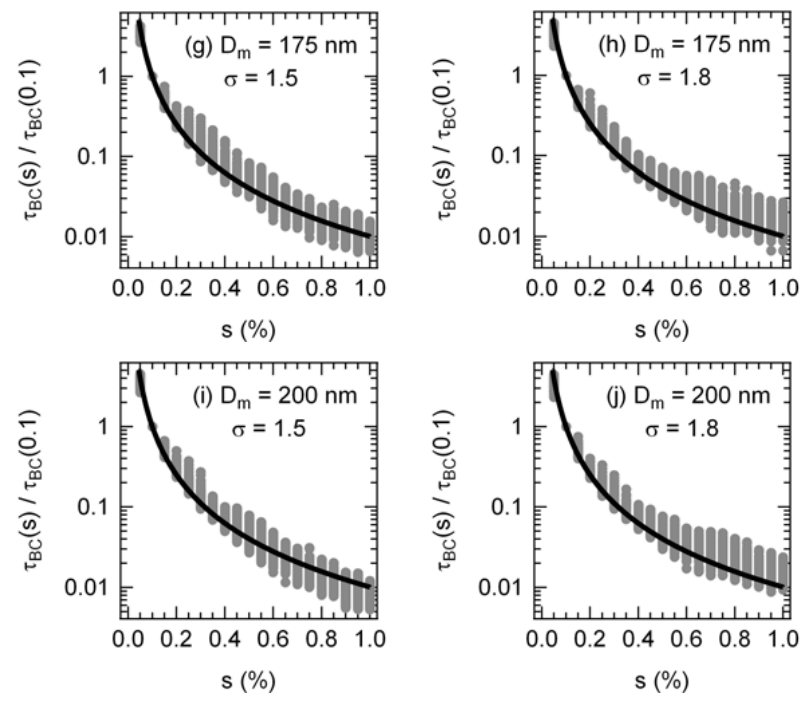

$\ln S=\frac{A}{D_{\text {drop }}}-\frac{B}{D_{\text {drop }}^{3}}$,

where

$A=\frac{4 M_{\mathrm{w}} \sigma_{\mathrm{w}}}{R T \rho_{\mathrm{w}}}, B=\frac{6 v m_{\mathrm{s}} M_{\mathrm{w}}}{\pi M_{\mathrm{s}} \rho_{\mathrm{w}}}$

and $m_{\mathrm{S}}$ is the mass concentration of solute. The critical saturation, $S_{\mathrm{c}}$, is derived analytically:

$\ln S_{\mathrm{c}}=\left(\frac{4 A^{3}}{27 B}\right)^{1 / 2}$,

and substituting Eq. (B4) into Eq. (B5) gives

$\ln S_{\mathrm{c}}=\frac{C}{\sqrt{m_{\mathrm{sc}}}}$,

where

$C=\left(\frac{2 A^{3} \pi \rho_{\mathrm{w}} M_{\mathrm{s}}}{81 v M_{\mathrm{w}}}\right)^{1 / 2}$

and $m_{\mathrm{sc}}$ is the mass concentration of the particle to become $\mathrm{CCN}$ active for the critical saturation. Here we consider the case that the small particle grows and subsequently has a sufficient coating amount to become $\mathrm{CCN}$ active for a given air supersaturation. We define a growth rate of coating on the particle $\left(V_{\mathrm{s}}\right)$, and when the particle has the sufficient coating to have $\mathrm{CCN}$ activity for a given air supersaturation, $m_{\mathrm{sc}}$ is approximately given by

$m_{\mathrm{sc}}=V_{\mathrm{s}} \tau_{\mathrm{sc}}$,

where $\tau_{\mathrm{sc}}$ is the time required for the particle to become $\mathrm{CCN}$ active due to condensational growth. Substituting (B8) into (B6) gives

$\tau_{\mathrm{sc}}=\frac{C^{2}}{V_{\mathrm{s}}\left(\ln S_{\mathrm{c}}\right)^{2}}$.

In order to derive a relationship between $\tau_{\mathrm{sc}}$ and a supersaturation $(s$, in $\%)$ for the same particle with the same growth rate $\left(V_{\mathrm{s}}\right)$, we divide $\tau_{\mathrm{sc}}(s)$ by $\tau_{\mathrm{sc}}(0.1)$ (i.e., the $\tau_{\mathrm{sc}}$ values for a supersaturation of any $s \%$ and $0.1 \%$, respectively) and obtain

$\frac{\tau_{\mathrm{sc}}(s)}{\tau_{\mathrm{sc}}(0.1)}=\left(\frac{\ln \left(1+\frac{0.1}{100}\right)}{\ln \left(1+\frac{s}{100}\right)}\right)^{2}$.

Fig. B1. Comparisons of the $F(s)\left(\equiv \tau_{\mathrm{BC}}(s) / \tau_{\mathrm{BC}}(0.1)\right)$ values as a function of $s$ (supersaturation, \%) calculated by Eq. (B1) (black curves) with the $\tau_{\mathrm{BC}}(s) / \tau_{\mathrm{BC}}(0.1)$ values derived from the calculation results using all combinations of the initial parameters shown in Table 1 between $0.05 \%$ and $1 \%$ with a $0.05 \%$ interval (gray circles) for each given lognormal BC size distribution shown in Fig. 1.
This expression indicates that $\tau_{\mathrm{sc}}(s)$ can be derived from $\tau_{\mathrm{sc}}(0.1)$. We need to derive the dependence of $\tau_{\mathrm{BC}}$ on supersaturation (i.e., the correction factor) in this Appendix when the same size distributions of particles with the same $V_{\mathrm{BC}}$ 
values are given. Applying Eq. (B10) for the case that the $\mathrm{BC}$ particle has a sufficient coating amount to become $\mathrm{CCN}$ active due to condensational growth, we can approximately replace $\tau_{\mathrm{sc}}$ by $\tau_{\mathrm{BC}}$ in Eq. (B10), and therefore Eq. (B1) is obtained.

Acknowledgements. This work was supported by the Ministry of Education, Culture, Sports, Science, and Technology and Japan Society for the Promotion of Science (MEXT/JSPS) through the Grant-in-Aid for Young Scientists (B) (KAKENHI) 23710029. This work was supported in part by the MEXT/JSPS Grant-inAid for Scientific Research (S) (KAKENHI) 23221001 and the global environment research fund of the Japanese Ministry of the Environment (A-0803 and A-1101). This study was conducted as a part of the Mega-Cities: Asia Task under the framework of the International Global Atmospheric Chemistry (IGAC) project. We thank T. Takemura, D. Goto, M. Kajino, and T. Y. Tanaka for providing helpful comments on this paper.

Edited by: A. Lauer

\section{References}

Adachi, K., and Buseck, P. R.: Atmospheric tar balls from biomass burning in Mexico, J. Geophys. Res., 116, D05204, doi:10.1029/2010JD015102, 2011.

Aquila, V., Hendricks, J., Lauer, A., Riemer, N., Vogel, H., Baumgardner, D., Minikin, A., Petzold, A., Schwarz, J. P., Spackman, J. R., Weinzierl, B., Righi, M., and Dall'Amico, M.: MADE-in: a new aerosol microphysics submodel for global simulation of insoluble particles and their mixing state, Geosci. Model Dev., 4, 325-355, doi:10.5194/gmd-4-325-2011, 2011.

Bardeen, C. G., Toon, O. B., Jensen, E. J., Marsh, D. R., and Harvey, V. L.: Numerical simulations of the three-dimensional distribution of meteoric dust in the mesosphere and upper stratosphere, J. Geophys. Res., 113, D17202, doi:10.1029/2007JD009515, 2008.

Bauer, S. E., Wright, D. L., Koch, D., Lewis, E. R., McGraw, R., Chang, L.-S., Schwartz, S. E., and Ruedy, R.: MATRIX (Multiconfiguration Aerosol TRacker of mIXing state): an aerosol microphysical module for global atmospheric models, Atmos. Chem. Phys., 8, 6003-6035, doi:10.5194/acp-8-60032008, 2008.

Bellouin, N., Rae, J., Jones, A., Johnson, C., Haywood, J., and Boucher, O.: Aerosol forcing in the Climate Model Intercomparison Project (CMIP5) simulations by HadGEM2-ES and the role of ammonium nitrate, J. Geophys. Res., 116, D20206, doi:10.1029/2011jd016074, 2011.

Binkowski, F. S. and Roselle, S. J.: Models-3 Community Multiscale Air Quality (CMAQ) model aerosol component. 1. Model description, J. Geophys. Res., 108(D6), 4183, doi:10.1029/2001JD001409, 2003.

Bond, T., Habib, G., and Bergstrom, R. W.: Limitations in the enhancement of visible light absorption due to mixing state, J. Geophys. Res., 111, D20211, doi:10.1029/2006JD007315, 2006.

Byun, D. W. and Ching, J. K. S.: Science algorithms of the EPA Models-3 Community Multi-scale Air Quality (CMAQ) modeling system, US Environmental Protection Agency, Office of Re- search and Development, Washington, DC, EPA/600/R-99/030, 1999.

Capaldo, K. P., Pilinis, C., and Pandis, S. N.: A computationally efficient hybrid approach for dynamic gas/aerosol transfer in air quality models, Atmos. Environ., 34, 3617-3627, 2000.

Chung, S. H. and Seinfeld, J. H.: Global distribution and climate forcing of carbonaceous aerosols, J. Geophys. Res., 107, 4407, doi:10.1029/2001JD001397, 2002.

Chung, S. H. and Seinfeld, J. H.: Climate response of direct radiative forcing of anthropogenic black carbon, J. Geophys. Res., 110, D11102, doi:10.1029/2004JD005441, 2005.

Cooke, W. F. and Wilson, J. J. N.: A global black carbon aerosol model, J. Geophys. Res., 101, D14, 19395-19409, 1996.

Cooke, W. F., Liousse, C., Cachier, H., and Feichter, J.: Construction of a $1 \times 1$ fossil fuel emission data set for carbonaceous aerosol and implementation and radiative impact in the ECHAM4 model, J. Geophys. Res., 104, 22137-22162, 1999.

Cooke, W. F., Ramaswamy, V., and Kasibhatla, P.: A general circulation model study of the global carbonaceous aerosol distribution, J. Geophys. Res., 107, 4279, doi:10.1029/2001JD001274, 2002.

Croft, B., Lohmann, U., and von Salzen, K.: Black carbon ageing in the Canadian Centre for Climate modelling and analysis atmospheric general circulation model, Atmos. Chem. Phys., 5, 19311949, doi:10.5194/acp-5-1931-2005, 2005.

Donner, L. J., Wyman, B. L., Hemler, R. S., Horowitz, L. W., Ming, Y., Zhao, M., Golaz, J. C., Ginoux, P., Lin, S. J., Schwarzkopf, M. D., Austin, J., Alaka, G., Cooke, W. F., Delworth, T. L., Freidenreich, S. M., Gordon, C. T., Griffies, S. M., Held, I. M., Hurlin, W. J., Klein, S. A., Knutson, T. R., Langenhorst, A. R., Lee, H. C., Lin, Y., Magi, B. I., Malyshev, S. L., Milly, P. C. D., Naik, V., Nath, M. J., Pincus, R., Ploshay, J. J., Ramaswamy, V., Seman, C. J., Shevliakova, E., Sirutis, J. J., Stern, W. F., Stouffer, R. J., Wilson, R. J., Winton, M., Wittenberg, A. T., and Zeng, F.: The dynamical core, physical parameterizations, and basic simulation characteristics of the atmospheric component AM3 of the GFDL global coupled model CM3, J. Climate, 24, 3484-3519, doi:10.1175/2011jcli3955.1, 2011.

Gery, M. W., Whitten, G. Z., Killus, J. P., and Dodge, M. C.: A photochemical kinetics mechanism for urban and regional scale computer modeling, J. Geophys. Res., 94, 12925-12956, 1989.

Goto, D., Nakajima, T., Takemura, T., and Sudo, K.: A study of uncertainties in the sulfate distribution and its radiative forcing associated with sulfur chemistry in a global aerosol model, Atmos. Chem. Phys., 11, 10889-10910, doi:10.5194/acp-1110889-2011, 2011a.

Goto, D., Schutgens, N. A. J., Nakajima, T., and Takemura T.: Sensitivity of aerosol to assumed optical properties over Asia using a global aerosol model and AERONET, Geophys. Res. Lett., 38, L17810, doi:10.1029/2011GL048675, 2011b.

Goto, D., Oshima, N., Nakajima, T., Takemura, T., and Ohara, T.: Impact of the aging process of black carbon aerosols on their spatial distribution, hygroscopicity, and radiative forcing in a global climate model, Atmos. Chem. Phys. Discuss., 12, 29801-29849, doi:10.5194/acpd-12-29801-2012, 2012.

Han, S., Kondo, Y., Oshima, N., Takegawa, N., Miyazaki, Y., Hu, M., Lin, P., Deng, Z., Zhao, Y., Sugimoto, N., and Wu, Y.: Temporal variations of elemental carbon in Beijing, J. Geophys. Res., 114, D23202, doi:10.1029/2009JD012027, 2009. 
Hansen, J., Sato, M., and Ruedy, R.: Radiative forcing and climate response, J. Geophys. Res., 102, 6831-6864, 1997.

Jacob, D. J.: Heterogeneous chemistry and tropospheric ozone, Atmos. Environ., 34, 2131-2159, 2000.

Jacobson, M. Z.: Development and application of a new air pollution modeling system, part II, Aerosol module structure and design, Atmos. Environ., 31, 131-144, doi:10.1016/13522310(96)00202-6, 1997

Jacobson, M. Z.: Strong Radiative Heating due to the Mixing State of Black Carbon in Atmospheric Aerosols, Nature, 409, 695697, 2001a.

Jacobson, M. Z.: GATOR-GCMM: A global- through urban-scale air pollution and weather forecast model: 1. Model design and treatment of subgrid soil, vegetation, roads, rooftops, water, sea ice, and snow, J. Geophys. Res., 106, 5385-5401, doi:10.1029/2000JD900560, 2001b.

Koch, D.: Transport and direct radiative forcing of carbonaceous and sulfate aerosols in the GISS GCM, J. Geophys. Res., 106, 20311-20332, 2001

Koch, D., Bond, T. C., Streets, D., Unger, N., and van der Werf, G. R.: Global impacts of aerosols from particular source regions and sectors, J. Geophys. Res., 112, D02205, doi:10.1029/2005JD007024, 2007.

Koch, D., Schulz, M., Kinne, S., McNaughton, C., Spackman, J. R., Balkanski, Y., Bauer, S., Berntsen, T., Bond, T. C., Boucher, O., Chin, M., Clarke, A., De Luca, N., Dentener, F., Diehl, T., Dubovik, O., Easter, R., Fahey, D. W., Feichter, J., Fillmore, D., Freitag, S., Ghan, S., Ginoux, P., Gong, S., Horowitz, L., Iversen, T., Kirkevåg, A., Klimont, Z., Kondo, Y., Krol, M., Liu, X., Miller, R., Montanaro, V., Moteki, N., Myhre, G., Penner, J. E., Perlwitz, J., Pitari, G., Reddy, S., Sahu, L., Sakamoto, H., Schuster, G., Schwarz, J. P., Seland, Ø., Stier, P., Takegawa, N., Takemura, T., Textor, C., van Aardenne, J. A., and Zhao, Y.: Evaluation of black carbon estimations in global aerosol models, Atmos. Chem. Phys., 9, 9001-9026, doi:10.5194/acp-9-9001-2009, 2009.

Koch, D., Bauer, S. E., Del Genio, A., Faluvegi, G., McConnell, J. R., Menon, S., Miller, R. L., Rind, D., Ruedy, R., Schmidt, G. A., and Shindell, D.: Coupled aerosol-chemistry-climate twentieth-century transient model investigation: trends in shortlived species and climate responses, J. Climate, 24, 2693-2714, doi:10.1175/2011jcli3582.1, 2011.

Koike, M., Takegawa, N., Moteki, N., Kondo, Y., Nakamura, H., Kita, K., Matsui, H., Oshima, N., Kajino, M., and Nakajima, T. Y.: Measurements of regional-scale aerosol impacts on cloud microphysics over the East China Sea: Possible influences of warm sea surface temperature over the Kuroshio ocean current, J. Geophys. Res., 117, D17205, doi:10.1029/2011JD017324, 2012.

Kondo, Y., Komazaki, Y., Miyazaki, Y., Moteki, N., Takegawa, N., Kodama, D., Deguchi, S., Nogami, M., Fukuda, M., Miyakawa, T., Morino, Y., Koike, M., Sakurai, H., and Ehara, K.: Temporal variations of elemental carbon in Tokyo, J. Geophys. Res., 111, D12205, doi:10.1029/2005JD006257, 2006.

Koren, I., Kaufman, Y. J., Remer, L. A., and Martins, J. V.: Measurement of the effect of Amazon smoke on inhibition of cloud formation, Science, 303, 1342-1345, 2004.

Lamarque, J.-F., Emmons, L. K., Hess, P. G., Kinnison, D. E., Tilmes, S., Vitt, F., Heald, C. L., Holland, E. A., Lauritzen, P. H., Neu, J., Orlando, J. J., Rasch, P. J., and Tyndall, G.
K.: CAM-chem: description and evaluation of interactive atmospheric chemistry in the Community Earth System Model, Geosci. Model Dev., 5, 369-411, doi:10.5194/gmd-5-369-2012, 2012.

Lee, Y. H., Lamarque, J.-F., Flanner, M. G., Jiao, C., Shindell, D. T., Berntsen, T., Bisiaux, M. M., Cao, J., Collins, W. J., Curran, M., Edwards, R., Faluvegi, G., Ghan, S., Horowitz, L. W., McConnell, J. R., Myhre, G., Nagashima, T., Naik, V., Rumbold, S. T., Skeie, R. B., Sudo, K., Takemura, T., and Thevenon, F.: Evaluation of preindustrial to present-day black carbon and its albedo forcing from ACCMIP (Atmospheric Chemistry and Climate Model Intercomparison Project), Atmos. Chem. Phys. Discuss. 12, 21713-21778, doi:10.5194/acpd-12-21713-2012, 2012.

Liu, J., Fan S., Horowitz, L. W., and Levy II, H.: Evaluation of factors controlling long-range transport of black carbon to the Arctic, J. Geophys. Res., 116, D04307, doi:10.1029/2010JD015145, 2011.

Liu, X., Penner, J. E., and Herzog, M.: Global modeling of aerosol dynamics: Model description, evaluation, and interactions between sulfate and nonsulfate aerosols, J. Geophys. Res., 110, D18206, doi:10.1029/2004JD005674, 2005.

Liu, X., Easter, R. C., Ghan, S. J., Zaveri, R., Rasch, P., Shi, X., Lamarque, J.-F., Gettelman, A., Morrison, H., Vitt, F., Conley, A., Park, S., Neale, R., Hannay, C., Ekman, A. M. L., Hess, P., Mahowald, N., Collins, W., Iacono, M. J., Bretherton, C. S., Flanner, M. G., and Mitchell, D.: Toward a minimal representation of aerosols in climate models: description and evaluation in the Community Atmosphere Model CAM5, Geosci. Model Dev., 5, 709-739, doi:10.5194/gmd-5-709-2012, 2012.

Lohmann, U., Feichter, J., Chuang, C. C., and Penner, J. E.: Predicting the number of cloud droplets in the ECHAM GCM, J. Geophys. Res., 104, 9169-9198, 1999.

Matsui, H., Koike, M., Kondo, Y., Takegawa, N., Kita, K. Miyazaki, Y., Hu, M., Chang S. Y., Blake, D. R., Fast, J. D., Zaveri, R. A., Streets, D. G., Zhang, Q., Zhu, T.: Spatial and temporal variations of aerosols around Beijing in summer 2006: Model evaluation and source apportionment, J. Geophys. Res., 114, D00G13, doi:10.1029/2008JD010906, 2009.

Meng, Z., Dabdub, D., and Seinfeld, J. H.: Size-resolved and chemically resolved model of atmospheric aerosol dynamics, J. Geophys. Res., 103, 3419-3435, 1998.

Menon, S., Hansen, J., Nazarenko, L., and Luo, Y.: Climate effects of black carbon aerosols in China and India, Science, 297, 2250 2253, 2002.

Moteki, N., Kondo, Y., Miyazaki, Y., Takegawa, N., Komazaki, Y., Kurata, G., Shirai, T., Blake, D. R., Miyakawa, T., and Koike, M.: Evolution of Mixing State of Black Carbon Particles: Aircraft Measurements over the Western Pacific in March 2004, Geophys. Res. Lett., 34, L11803, doi:10.1029/2006GL028943, 2007.

Myhre, G., Samset, B. H., Schulz, M., Balkanski, Y., Bauer, S., Berntsen, T. K., Bian, H., Bellouin, N., Chin, M., Diehl, T., Easter, R. C., Feichter, J., Ghan, S. J., Hauglustaine, D., Iversen, T., Kinne, S., Kirkevåg, A., Lamarque, J.-F., Lin, G., Liu, X., Luo, G., Ma, X., Penner, J. E., Rasch, P. J., Seland, Ø., Skeie, R. B., Stier, P., Takemura, T., Tsigaridis, K., Wang, Z., Xu, L., Yu, H., Yu, F., Yoon, J.-H., Zhang, K., Zhang, H., and Zhou, C.: Radiative forcing of the direct aerosol effect from AeroCom Phase II simulations, Atmos. Chem. Phys. Discuss., 12, 22355-22413, doi:10.5194/acpd-12-22355-2012, 2012. 
Oshima, N., Koike, M., Zhang, Y., Kondo, Y., Moteki, N., Takegawa, N., and Miyazaki, Y.: Aging of black carbon in outflow from anthropogenic sources using a mixing state resolved model: Model development and evaluation, J. Geophys. Res., 114, D06210, doi:10.1029/2008JD010680, 2009a.

Oshima, N., Koike, M., Zhang, Y., and Kondo, Y.: Aging of black carbon in outflow from anthropogenic sources using a mixing state resolved model: 2. Aerosol optical properties and cloud condensation nuclei activities, J. Geophys. Res., 114, D18202, doi:10.1029/2008JD011681, 2009b.

Oshima, N., Kondo, Y., Moteki, N., Takegawa, N., Koike, M., Kita, K., Matsui, H., Kajino, M., Nakamura, H., Jung, J. S., and Kim, Y. J.: Wet removal of black carbon in Asian outflow: Aerosol Radiative Forcing in East Asia (A-FORCE) aircraft campaign, J. Geophys. Res., 117, D03204, doi:10.1029/2011JD016552, 2012.

Pandis, S. N., Wexler, A. S., and Seinfeld, J. H.: Secondary organic aerosol formation and transport-II. Predicting the ambient secondary organic aerosol size distribution, Atmos. Environ. A, 27, 2403-2416, 1993.

Park, R. J., Jacob, D. J., Palmer, P. I., Clarke, A. D., Weber, R. J., Zondlo, M. A., Eisele, F. L., Bandy, A. R., Thornton, D. C., Sachse, G. W., and Bond, T.: Export efficiency of black carbon aerosol in continental outflow: Global implications, J. Geophys. Res., 110, D11205, doi:10.1029/2004JD005432, 2005.

Petters, M. D. and Kreidenweis, S. M.: A single parameter representation of hygroscopic growth and cloud condensation nucleus activity, Atmos. Chem. Phys., 7, 1961-1971, doi:10.5194/acp-71961-2007, 2007.

Ramanathan, V. and Carmichael, G.: Global and regional climate changes due to black carbon, Nat. Geosci., 1, 221-227, 2008.

Ramanathan, V., Crutzen, P. J., Kiehl, J. T., and Rosenfeld, D.: Aerosols, Climate, and the Hydrological Cycle, Science, 294, 2119-2124, 2001.

Riemer, N., Vogel, H., and Vogel, B.: Soot aging time scales in polluted regions during day and night, Atmos. Chem. Phys., 4, 1885-1893, doi:10.5194/acp-4-1885-2004, 2004.

Riemer, N., West, M., Zaveri, R. A., and Easter, R. C.: Estimating soot aging time scales with a particle-resolved aerosol model, J. Aerosol Sci., 41, 143-158, 2010.

Russo, R. S., Talbot, R. W., Dibb, J. E., Scheuer, E., Seid, G., Jordan, C. E., Fuelberg, H. E., Sachse, G. W., Avery, M. A., Vay, S. A., Blake, D. R., Blake, N. J., Atlas, E., Fried, A., Sandholm, S. T., Tan, D., Singh, H. B., Snow, J., and Heikes, B. G.: Chemical composition of Asian continental outflow over the western Pacific: Results from Transport and Chemical Evolution over the Pacific (TRACE-P), J. Geophys. Res., 108, 8804, doi:10.1029/2002jd003184, 2003.

Sakurai, H., Park, K., McMurry, P. H., Zarling, D. D., Kittelson, D. B., and Ziemann, P. J.: Size-dependent mixing characteristics of volatile and nonvolatile components in diesel exhaust aerosols, Environ. Sci. Technol., 34, 5487-5495, 2003.

Schwarz, J. P., Spackman, J. R., Fahey, D. W., Gao, R. S., Lohmann, U., Stier, P., Watts, L. A., Thomson, D. S., Lack, D. A., Pfister, L., Mahoney, M. J., Baumgardner, D., Wilson, J. C., and Reeves, J. M.: Coatings and their enhancement of black carbon light absorption in the tropical atmosphere, J. Geophys. Res., 113, D03203, doi:10.1029/2007JD009042, 2008a.
Schwarz, J. P., Gao, R. S., Spackman, J. R., Watts, L. A., Thomson, D. S., Fahey, D. W., Ryerson, T. B., Peischl, J., Holloway, J. S., Trainer, M., Frost, G. J., Baynard, T., Lack, D. A., de Gouw, J. A., Warneke, C., and Del Negro, L. A.: Measurement of the mixing state, mass, and optical size of individual black carbon particles in urban and biomass burning emissions, J. Geophys. Res., 35, L13810, doi:10.1029/2008GL033968, 2008b.

Seinfeld, J. H. and Pandis, S. N.: Atmospheric Chemistry and Physics: From Air Pollution to Climate Change, 2nd ed., John Wiley \& Sons, New York, USA, 2006.

Skeie, R. B., Berntsen, T., Myhre, G., Pedersen, C. A., Ström, J., Gerland, S., and Ogren, J. A.: Black carbon in the atmosphere and snow, from pre-industrial times until present, Atmos. Chem. Phys., 11, 6809-6836, doi:10.5194/acp-11-6809-2011, 2011.

Stier, P., Feichter, J., Kinne, S., Kloster, S., Vignati, E., Wilson, J., Ganzeveld, L., Tegen, I., Werner, M., Balkanski, Y., Schulz, M., Boucher, O., Minikin, A., and Petzold, A.: The aerosol-climate model ECHAM5-HAM, Atmos. Chem. Phys., 5, 1125-1156, doi:10.5194/acp-5-1125-2005, 2005.

Stier, P., Seinfeld, J. H., Kinne, S., Feichter, J., and Boucher, O.: Impact of nonabsorbing anthropogenic aerosols on clearsky atmospheric absorption, J. Geophys. Res., 111, D18201, doi:10.1029/2006JD007147, 2006.

Takegawa, N., Miyakawa, T., Kuwata, M., Kondo, Y., Zhao, Y., Han, S., Kita, K., Miyazaki, Y., Deng Z., Xiao, R., Hu, M., Pinxteren, D. van, Herrmann, H., Hofzumahaus, A., Holland F., Wahner, A., Blake, D. R., Sugimoto, N., and Zhu, T.: Variability of submicron aerosol observed at a rural site in Beijing in the summer of 2006, J. Geophys. Res., 114, D00G05, doi:10.1029/2008JD010857, 2009.

Takemura, T., Nozawa, T. T., Emori, S., Nakajima, T. Y., and Nakajima, T.: Simulation of climate response to aerosol direct and indirect effects with aerosol transport-radiation model, J. Geophys. Res., 110, D02202, doi:10.1029/2004JD005029, 2005.

Toner, S. M., Sodeman, D. A., and Prather, K. A.: Single particle characterization of ultrafine and accumulation mode particles from heavy duty diesel vehicles using aerosol time-of-flight mass spectrometry, Environ. Sci. Technol., 40, 3912-3921, 2006.

Tsyro, S., Simpson, D., Tarrason, L., Klimont, Z., Kupiainen, K., Pio, C., and Yttri, K. E.: Modeling of elemental carbon over Europe, J. Geophys. Res., 112, D23S19, doi:10.1029/2006JD008164, 2007.

Wehner, B., Philippin, S., Wiedensohler, A., Scheer, V., and Vogt, R.: Variability of non-volatile fractions of atmospheric aerosol particles with traffic influence, Atmos. Environ., 38, 6081-6090, doi:10.1016/j.atmosenv.2004.08.015, 2004.

Weingartner, E., Burtscher, H., and Baltensperger, U.: Hygroscopic properties of carbon and diesel soot particles, Atmos. Environ., 31, 2311-2327, 1997.

Whitby, K. T.: The physical characteristics of sulfur aerosols, Atmos. Environ., 12, 135-159, 1978.

Wilson, J., Cuvelier, C., and Raes, F.: A modeling study of global mixed aerosol fields, J. Geophys. Res., 106, 34081-34108, 2001.

$\mathrm{Yu}, \mathrm{S}$.: Role of organic acids (formic, acetic, pyruvic and oxalic) in the formation of cloud condensation nuclei $(\mathrm{CCN})$ : a review, Atmos. Res., 53, 185-217, 2000. 
Yukimoto, S., Adachi, Y., Hosaka, M., Sakami, T., Yoshimura, H., Hirabara, M., Tanaka, T. Y., Shindo, E., Tsujino, H., Deushi, M., Mizuta, R., Yabu, S., Obata, A., Nakano, H., Koshiro, T., Ose, T., and Kitoh, A.: A new global climate model of Meteorological Research Institute: MRI-CGCM3 -Model description and basic performance-, J. Meteor. Soc. Japan, 90A, 23-64, doi:10.2151/jmsj.2012-A02, 2012.
Zhang, Y., Pun, B., Vijayaraghavan, K., Wu, S. Y., Seigneur, C., Pandis, S. N., Jacobson, M. Z., Nenes, A., and Seinfeld, J. H.: Development and application of the model of aerosol dynamics, reaction, ionization, and dissolution (MADRID), J. Geophy. Res., 109, D01202, doi:10.1029/2003JD003501, 2004. 